\title{
Menthol-modified BSA nanoparticles for glioma targeting therapy using an energy restriction strategy
}

Jianming Liang ${ }^{1,2,3}$, Ying Zhu' ${ }^{2}$, Caifang Gao ${ }^{1,3}$, Chengli Ling ${ }^{4}$, Jing Qin ${ }^{1}$, Qi Wang ${ }^{5}$, Yongzhuo Huang ${ }^{6}$, Weigen Lu ${ }^{3}$ and Jianxin Wang (1)

\begin{abstract}
Current chemotherapeutics for glioma are not sufficiently effective due to their low tolerance and poor blood-brain barrier (BBB) permeability. Energy restriction based on co-delivery of albendazole (Abz) and nano-silver has been proven to suppress tumor growth without adverse effects. Accordingly, menthol was conjugated to BSA (MeB) to overcome the BBB-permeability issue. In this study, Abz-loaded MeB-silver nanoparticles (MBS-Abz) were developed by self-assembly of $\mathrm{MeB}$, albendazole and nano silver for glioma targeting therapy. The nanoparticle entered the brain across the BBB and specifically accumulated in the glioma region. MeB delivered the nanoparticles across the brain capillary endothelial cell monolayer by promoting internalization and BBB disruption. MBS-Abz hindered ATP generation via the inhibition of glycolytic and mitochondrial pathways both in vitro and in vivo. The anti-glioma mechanisms of energy restriction were related to the cytotoxicity, proliferation inhibition, cell cycle arrest, and apoptosis induced by ATP exhaustion, and the effects of MBS-Abz were significantly better than those induced by monotherapy nanoparticles or unmodified nanoparticles. These results demonstrated that by combining the energy restriction effect of albendazole and nano silver, as well as the BBB penetration ability of menthol, MBS-Abz achieves superior anti-glioma efficacy and can be an effective strategy for glioma therapy.
\end{abstract}

\section{Introduction}

Cancer has replaced cardiovascular disease as the leading cause of death in the United States ${ }^{1}$. Although many antitumor drugs have been developed, the global burden of cancer is still high. Brain cancers account for approximately $3 \%$ of the global cancer cases ${ }^{2}$, among which, gliomas are associated with high morbidity and mortality. Chemotherapy is a major therapeutic modality for glioma. Although cytotoxic agents, such as

\footnotetext{
Correspondence: Yongzhuo Huang (yzhuang@simm.ac.cn) or

Weigen Lu (sipiluwg@163.com) or Jianxin Wang (jxwang@fudan.edu.cn)

1Department of Pharmaceutics, School of Pharmacy, Fudan University \& Key Laboratory of Smart Drug Delivery, Ministry of Education, 201203 Shanghai, PR China

${ }^{2}$ Institute of Tropical Medicine, Guangzhou University of Chinese Medicine, 510006 Guangzhou, PR China

Full list of author information is available at the end of the article.

These authors contributed equally: Jianming Liang, Ying Zhu
}

nitrosoureas and platinum-based drugs, can curb the growth of glioma cells, they also cause serious adverse effects, such as nephrotoxicity by cisplatin and pulmonary toxicity by nitrosoureas ${ }^{3,4}$, which lead to poor tolerance and limited efficacy ${ }^{5}$. Therefore, the need to develop safe and effective strategies for glioma treatment is pressing.

Since tumor cells proliferate rapidly and infinitely ${ }^{6}$, they consume substantial amounts of energy to maintain this abnormal growth process ${ }^{7}$. Abnormal energy metabolism is an important physiological characteristic of glioma ${ }^{8,9}$. Adenosine triphosphate (ATP) is the most direct source of energy, and compared with normal cells, glioma cells are more sensitive to ATP levels ${ }^{10}$. Energy restriction was confirmed to effectively inhibit glioma growth ${ }^{11,12}$. Thus, energy metabolism inhibition may be an effective approach for glioma therapy. Glioma cells mainly generate ATP via the glycolytic pathway rather than oxidative 
phosphorylation, which is known as the Warburg effect. The inhibition of glycolytic enzyme activities can effectively decrease ATP production and cell proliferation ${ }^{13}$. When glycolysis is inhibited, tumor cells compensatively increase ATP synthesis via the mitochondrial pathway to meet the need for physiological functions ${ }^{14}$, which renders the curative effect of monotherapy (glycolysis inhibitor only) unsatisfactory ${ }^{15}$. Therefore, ideal energy inhibition should block ATP synthase by simultaneously inhibiting the glycolytic and mitochondrial pathways. In our previous study, we developed a novel antitumor strategy based on energy restriction by utilizing albendazole (Abz) and silver nanoparticles (SNP) as glycolysis inhibitors and mitochondrial inhibitors, respectively ${ }^{16}$. Abz inhibits glycolytic enzyme activities and downregulates hypoxia-inducible factor I expression, thus inhibiting glycolysis ${ }^{17,18}$. Moreover, Abz nanoparticles efficiently suppressed the growth of solid tumors ${ }^{19}$, and Abz decreased tumor markers, in addition to being well tolerated in a phase I clinical trial ${ }^{20}$. SNP reduced mitochondrial function and inhibited ATP generation via the mitochondrial pathway ${ }^{21,22}$. Therefore, our strategy based on the combination of Abz and SNP was expected to effectively and safely restrict glioma growth, even though no cytotoxic antitumor agent was used during the treatment.

The delivery of therapeutic agents is more difficult in glioma than in other tumors because of the blood-brain barrier (BBB). The BBB is a continuous endothelial monolayer coupled by tight junctions (TJs), with extremely low permeability for the exchange of materials ${ }^{23}$. For brain targeting, drug-delivery strategies, such as receptormediated transcytosis and BBB disruption, effectively enhance the distribution of drugs to the brain via transcellular and paracellular pathways, respectively ${ }^{24,25}$. However, receptor-mediated transcytosis is strongly limited by the amount of receptors and their recycling ${ }^{26}$. To maximize $\mathrm{BBB}$ penetrability, BBB disruption methods, such as focused ultrasound, which delivers drugs to the brain by directly opening TJs, have been frequently applied $^{27,28}$. However, BBB disruption is commonly associated with severe side effects ${ }^{29}$. Thus, it is important to find a safe and effective way for BBB opening.

During the clinical practice of traditional Chinese medicine for thousands of years, some aromatic resuscitation drugs, such as borneol, musk and corn mint, which are also referred to as messenger drugs, have been used to guide other drugs to specific organs, especially the brain ${ }^{30}$. Their effect is similar to that of targeting ligands for drug delivery in the brain. In addition to their prominent ability to improve the efficacy of drugs treating brain diseases, the safety of messenger drugs as brain penetration enhancers (BPEs) has been widely confirmed ${ }^{31-33}$. Although the physical mixture of BPEs and drug delivery systems, the most commonly used method, may enhance brain penetration $^{34}$, there are still some limitations. First, while it is very likely that the aromatic resuscitation components reach the $\mathrm{BBB}$, the nano-carriers may still circulate in other parts of the body, making it difficult for the active substance to pass the $\mathrm{BBB}$ and reach the brain tumor site. Second, the physical mixture of BPEs and drug delivery systems may open the BBB for too long, causing the entrance of harmful substances into the brain and possible damage to the brain tissue. Third, because the delivery efficiency of simple mixing is very low, a higher dose of aromatic resuscitation components might be required, which might cause severe damage to the blood vessels and other organs ${ }^{31}$. Chemical coupling could be an effective method ${ }^{35,36}$ to overcome these shortcomings by synchronizing delivery of aromatic resuscitation components and nanoparticles at the $\mathrm{BBB}$, and potentially enhancing the water solubility of BPEs. Menthol, the main active component of corn mint, is one of the most widely used aromatic resuscitation drugs in traditional Chinese medicine. This molecule enhances the penetration of many drugs into the brain by downregulating the level of TJ proteins ${ }^{37,38}$.

Penetration of the brain tissue across the BBB is not sufficient, as the nanoparticles need to accumulate in satisfactory concentrations in the glioma region. Tumor cells need a substantial amount of nutrients, such as albumin, for rapid proliferation ${ }^{39}$. Specifically, glioma cells up-regulate the expression of albumin-binding protein and secreted protein acidic and rich in cysteine (SPARC) to uptake albumin ${ }^{40,41}$. However, SPARC-albumin binding has not attracted much attention. Despite the limited studies reporting that the SPARC pathway can be applied in glioma-targeting biomimetic delivery, SPARC was shown to prominently improve treatment outcome ${ }^{42,43}$. Moreover, albumin can be modified with functional ligands and encapsulate various antineoplastic drugs, thus constituting an ideal and natural glioma-targeting carrier. For example, menthol-modified bovine serum albumin $(\mathrm{MeB})$, prepared by conjugating 8-mercaptomenthone with bovine serum albumin (BSA), not only induces BBB disruption, but also penetrates the BBB directly through the pineal body pathway ${ }^{44}$. Thus, $\mathrm{MeB}$ can be used to deliver drugs to the brain safely and effectively and allow the selective accumulation of these drugs in the glioma region via SPARC-mediated glioma targeting of BSA.

In this study, we developed menthol-modified albumin as a carrier to simultaneously deliver Abz and SNP to the glioma region across the $\mathrm{BBB}$ (Scheme 1), as the subsequent inhibition of energy metabolism achieved by the combination of Abz and SNP would drastically deplete cellular ATP via glycolytic and mitochondrial pathways, thus causing proliferation inhibition, cell cycle arrest and apoptosis of tumor cells. Therefore, we hypothesized that 

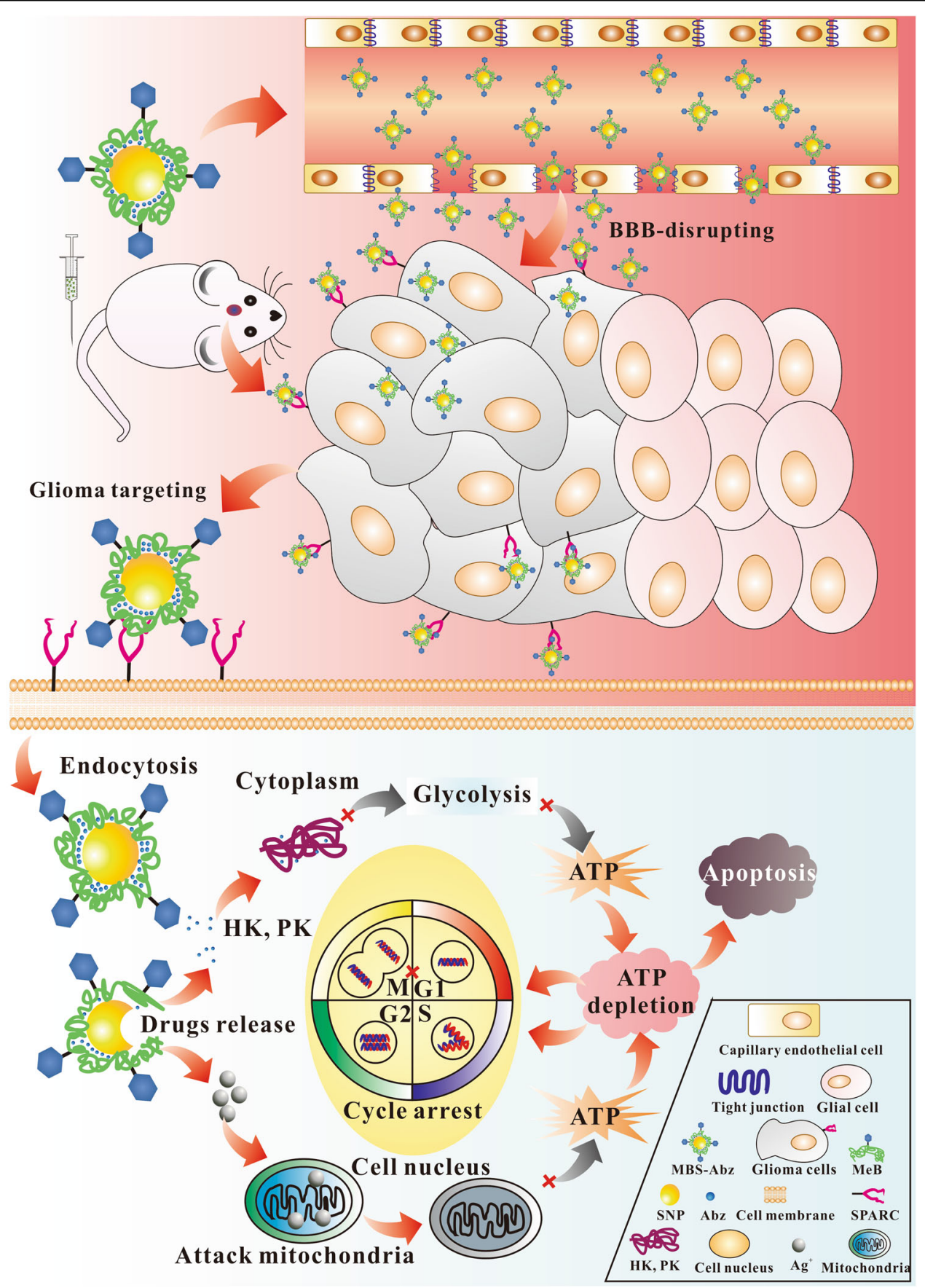

Scheme 1 Illustration of the antiglioma mechanism of MBS-Abz

this approach would effectively deliver energy metabolism inhibitors into the brain and tumor sites and strongly suppress the growth of glioma in a safe manner.

\section{Materials and methods}

Materials

Bovine serum albumin, coumarin 6 (Cou 6), Tris (2-carboxyethyl) phosphine hydrochloride (TCEP.HCl) and cytochalasin D were obtained from Aladdin Corp. (Shanghai, China). Hoechst 33342, propidium iodide, sodium azide, chlorpromazine, colchicine, methyl$\beta$-cyclodextrin and 4',6-diamidino-2-phenylindole (DAPI) were purchased from Sigma Aldrich (St. Louis, MI, USA). Filipin, 5,5'-dithiobis-(2-nitrobenzoic acid) (DTNB), paramentha-8-thiol-3-one and 2-iminothiolane hydrochloride were purchased from I\&K Chemical Ltd. (Shanghai, 
China). Tetraethylbenzimidazolylcarbocyanine iodide (JC-1) dye and 1,1'-dioctadecyl-3,3,3',3'-tetramethylind otricarbocyanine iodide (DIR) were from Beijing Fanbo Science and Technology Co., Ltd. (Beijing, China). SB 203580 was obtained from Medchem Express Co., Ltd. (Shanghai, China). Annexin V-FITC was purchased from BioVision Inc. (Milpitas, CA, USA). Albendazole (Abz) was provided by Dalian Meilun Biology Technology Co., Ltd. (Dalian, China). Carboxyfluorescein diacetate and succinimidyl ester (CFDA-SE) was purchased from Beyotime Institute of Biotechnology (Beijing, China). Silver nitrate, sodium borohydride, and tetrabutylammonium bromide (TBAB) were purchased from Sinopharm Chemical Reagent Co., Ltd. (Shanghai, China). Adenosine triphosphate (ATP) and adenosine diphosphate (ADP) were purchased from Adamas-beta .

\section{Synthesis of menthol-modified BSA}

As menthol does not have any reactive functional group to conjugate with BSA, the menthol analog para-mentha8-thiol-3-one, with the skeleton structure of menthol, was used to modify BSA. Briefly, 2-iminothiolane hydrochloride solution $\left(70 \mathrm{mg} \mathrm{mL}^{-1}, 100 \mu \mathrm{L}\right)$ was added dropwise slowly into BSA solution $\left(100 \mathrm{mg} \mathrm{L}^{-1}, 1 \mathrm{~mL}, \mathrm{pH}=\right.$ 9.0) and incubated at room temperature for $30 \mathrm{~min}$. Then 1,4-butanediol diglycidyl ether ethanol solution $(50 \%, \mathrm{v} / \mathrm{v})$ was added to the reaction solution and incubated for a further $4 \mathrm{~h}$. The free small molecule was removed by using a Sephadex LH-20 column and the protein solution was collected, combined with sodium carbonate solution $\left(1 \mathrm{~mol} \mathrm{~L}^{-1}\right)$ to a final concentration of $0.1 \mathrm{~mol} \mathrm{~L}^{-1}$, mixed with $8 \mathrm{~mL}$ para-mentha-8-thiol-3-one ethanol solution $\left(10 \mathrm{mg} \mathrm{mL}^{-1}\right)$ and stirred for $24 \mathrm{~h}$ at room temperature. The protein was precipitated with ethanol-ethyl acetate solution $(1: 1, \mathrm{v} / \mathrm{v})$, collected, dissolved in water, dialyzed against water and filtered through a $0.22 \mu \mathrm{m}$ syringe filter. The thus-formed modified BSA was named MeB (menthol-modified BSA).

\section{Physical characterization of MeB}

As para-mentha-8-thiol-3-one reacted with BSA through the thiol groups, the modification rate of $\mathrm{MeB}$ could be monitored by the decrease of thiol in the reaction solution. The modified BSA concentration was quantified by using a bicinchoninic acid assay (BCA) protein analysis kit (Beyotime, Shanghai, China), and the thiol concentration was quantified using a DTNB assay. The modification rate (MR) was calculated according to Equation (1):

$$
M R(\%)=\frac{\left(c_{0}-c_{t}\right) / p_{m b}}{c_{B S A} / p_{B S A}} \times 100 \%
$$

where $c_{O}\left(\mathrm{mmol} \mathrm{L}^{-1}\right)$ and $c_{t}\left(\mathrm{mmol} \mathrm{L}^{-1}\right)$ are the thiol contents of $\mathrm{MeB}$ at the beginning and end respectively, and $c_{B S A}$ is the primary amine content of BSA. $p_{m b}$ and $p_{B S A}$ are the protein concentrations of $\mathrm{MeB}$ and $\mathrm{BSA}$, respectively.

The molecular weight of $\mathrm{MeB}$ was determined using by $10 \%$ sodium dodecyl sulfate-polyacrylamide gel electrophoresis (SDS-PAGE). The lipophilicity of $\mathrm{MeB}$ was analyzed with high-performance liquid chromatography (HPLC) as reported previously ${ }^{45}$.

\section{Preparation of drug-loaded nanoparticles}

Albumin loaded nanoparticles were prepared as reported previously ${ }^{16}$. First, SNP was produced using the seedmediated method ${ }^{46}$. The protein solution (BSA or MeB) was reduced by TCEP, and mixed with SNP and Abz. After $2 \mathrm{~h}$, the reaction solution was sonicated at $4{ }^{\circ} \mathrm{C}$ and dialyzed for $1 \mathrm{~h}$ against water. The formed nanoparticles (Abz-loaded BSA-silver nanoparticles (BS-Abz) and Abzloaded MeB-silver nanoparticles (MBS-Abz)) were collected by centrifugation at $8000 \mathrm{rpm}$ for $20 \mathrm{~min}$ at $4{ }^{\circ} \mathrm{C}$, resuspended in ultrapure water, and filtered through a $0.22 \mu \mathrm{m}$ syringe filter. The Abz-loaded BSA and MeB nanoparticles were designated $\mathrm{B}-\mathrm{Abz}$ and $\mathrm{MB}-\mathrm{Abz}$, respectively, and SNP-loaded BSA and $\mathrm{MeB}$ nanoparticles were designated BS and MBS, respectively. Finally, the concentration of $\mathrm{Abz}$ in nanoparticles was determined with an ultra performance liquid chromatography (UPLC) system (ACQUITY UPLC, Waters Corp., Milford, MA, USA). Fluorescent dye-loaded albumin nanoparticles (Cou 6 or DIR) were prepared as the procedure above.

\section{Characterization of the nanoparticles}

The particle size, zeta potential and polydispersity index (PDI) were measured by dynamic light scattering (Malvern Instruments Ltd., Worcestershire, UK). The morphological characteristics of the nanoparticles were measured by transmission electron microscopy (TEM). The drug-loading efficiency (DL) and encapsulation efficiency (EE) of Abz were calculated using Equations (2) and (3), respectively:

$$
\begin{aligned}
& D L=\frac{p_{A b z} \times V}{m_{N P}} \times 100 \% \\
& E E=\frac{p_{A b z} \times V}{m_{\text {total }}} \times 100 \%
\end{aligned}
$$

where $p_{A b z}\left(\mathrm{mg} \mathrm{mL}^{-1}\right)$ is the mass concentration of $\mathrm{Abz}$, $V(\mathrm{~mL})$ is the solution volume, $m_{N P}(\mathrm{mg})$ is the weight of total nanoparticles, and $m_{\text {total }}(\mathrm{mg})$ is the weight of Abz input.

\section{In vivo imaging of the nanoparticles in an orthotopic glioma model}

C6 glioma cells (Cell Bank of Type Culture Collection of Chinese Academy of Sciences, Shanghai, China) were 
cultured in Dulbecco's modified Eagle's medium (DMEM, GIBCO-Invitrogen, Waltham, MA, USA) supplemented with $10 \%$ fetal bovine serum (FBS, Gemini Bio-Products, West Sacramento, CA, USA), $2 \mathrm{mmol} \mathrm{L}^{-1}$ glutamine and $1 \%$ penicillin/streptomycin at $37^{\circ} \mathrm{C}$ in a $5 \% \mathrm{CO}_{2}$ humidified incubator (Thermo Fisher Scientific, Waltham, MA, USA).

An orthotopic glioma model was established in nude mice using the C6 glioma cell line. C6 cells in logarithmic growth phase were digested in trypsin, adjusted to a cell density of $8 \times 10^{5}$ in $5 \mu \mathrm{L}$ phosphate-buffered saline (PBS) solution. The nude mice were first anesthetized with $10 \%$ pentobarbital, and then the cell suspension was slowly inoculated into the caudatoputamen at a depth of $4 \mathrm{~mm}$. After implantation, the needle was slowly withdrawn from the brain, and the bone hole and skin incision were closed using medical glue. Two weeks later, the mice were randomly divided into two groups and injected intravenously with BSA-DIR and MeB-DIR. In vivo fluorescent images were taken by using the In Vivo imaging system at $1,2,4$, 8,12 , and $24 \mathrm{~h}$ after injection. After $24 \mathrm{~h}$, the mice were anesthetized and perfused with $4 \%$ paraformaldehyde, and their organs removed carefully and visualized using the imaging system.

\section{In vitro BBB penetration of the nanoparticles}

The in vitro $\mathrm{BBB}$ model was prepared using brain capillary endothelial cells (BCECs). The cells were plated at a density of $5 \times 10^{4}$ cells $\mathrm{cm}^{-2}$ into the apical chambers of transwell ${ }^{\circledast}$ cell culture plates (Corning, Corning, NY, USA). After 7 days in culture, the transendothelial electrical resistance (TEER) of cells was measured to test the tightness of the formed model. Only the cell models with TEER values higher than $200 \Omega \cdot \mathrm{cm}^{2}$ were selected for the penetration study. The nanoparticles (BSA-Cou 6 or MeB-Cou 6) and Hanks' Balanced Salt Solution (HBSS) were separately added to the donor chambers and receiver chambers. After $0.5,1,2$, and $4 \mathrm{~h}, 200 \mu \mathrm{L}$ of sample was removed from each receiver chamber for measurement, and immediately replaced with $200 \mu \mathrm{L}$ of HBSS solution. The transport efficiency (TE) of nanoparticles was evaluated via fluorescent quantitation using a fluorescence spectrophotometer and calculated as per Equation (4):

$$
T E=\frac{C_{t} \times V_{1}+C_{t-1} \times V_{2}}{C_{A} \times V_{A}} \times 100 \%
$$

where $C_{t}, C_{t-1}$ and $C_{A}$ are the concentration $\left(\mathrm{nmol} \mathrm{mL} L^{-1}\right)$ of the receiver chamber at the time point and the initial concentration $\left(\mathrm{nmol} \mathrm{mL}^{-1}\right)$ in the donor chamber respectively. $V_{1}, V$ and $V_{A}$ were the volume $(\mathrm{mL})$ of receiver chamber, sample, and donor solutions, respectively.
The apparent permeability coefficient $\left(P_{a p p}\right)$ was calculated as per Equation (5):

$$
P_{a p p}=\frac{d C / d t \times V}{C_{0} / A}
$$

where $d C / d t$ is the permeability rate $\left(\mathrm{nmol} \mathrm{s}^{-1}\right), V$ is the volume of receiver chamber solution, $C_{O}$ is the initial concentration $\left(\mathrm{nmol} \mathrm{mL}{ }^{-1}\right)$ in the donor chamber, and $A$ is the surface area $\left(\mathrm{cm}^{2}\right)$ of the filter membrane.

\section{Endocytic mechanism}

When the BCECs and C6 cells reached the logarithmic growth phase, they were digested in trypsin, seeded at a density of $3 \times 10^{5}$ cells well $^{-1}$ in 24-well plates, and then incubated with BSA-Cou 6 and MeB-Cou 6 (the concentration of C6 was $50 \mathrm{ng} \mathrm{mL}^{-1}$ for each group) for $4 \mathrm{~h}$ at $37^{\circ} \mathrm{C}$. After incubation, the cells were harvested, washed with PBS twice and monitored by flow cytometry (FACS Calibur, BD, Franklin Lakes, NJ, USA). The endocytosis of the nanoparticles was analyzed using fluorescence microscopy as well.

To elucidate the endocytic mechanism of the nanoparticles in BCECs and C6 cells, various endocytosis inhibitors were used in this section. Briefly, the cells were pretreated for $1 \mathrm{~h}$ at $37^{\circ} \mathrm{C}$ with different types of endocytosis inhibitors separately $\left(5 \mu \mathrm{mol} \mathrm{L}^{-1}\right.$ methyl$\beta$-cyclodextrin (M-CD), $1 \mu \mathrm{g} \mathrm{mL} \mathrm{L}^{-1}$ cytochalasin $\mathrm{D}(\mathrm{CytD})$, $1 \mathrm{mg} \mathrm{mL}^{-1}$ carrier proteins (BSA/MeB), $5 \mu \mathrm{g} \mathrm{mL}^{-1}$ filipin, $10 \mu \mathrm{g} \mathrm{mL}^{-1}$ chlorpromazine (CPZ), $3 \mathrm{mg} \mathrm{mL}^{-1}$ sodium azide $\left(\mathrm{NaN}_{3}\right), 10 \mu \mathrm{g} \mathrm{mL}^{-1}$ colchicine $\left.(\mathrm{Col})\right)$. The cells with no inhibitors were used as controls. Different nanoparticles (BSA-Cou 6 and MeB-Cou 6) were added to the cells, and cultured at $37^{\circ} \mathrm{C}$ for $4 \mathrm{~h}$. The cells were finally harvested and analyzed by flow cytometry.

To investigate the interaction between albumin nanoparticles and SPARC in BCECs and C6 cells, SB 203580 was chosen to inhibit SPARC expression. Briefly, the cells were pretreated for $24 \mathrm{~h}$ at $37^{\circ} \mathrm{C}$ with $\mathrm{SB} 203580$ $\left(20 \mu \mathrm{g} \mathrm{mL}^{-1}\right)$, washed with PBS, incubated with the nanoparticle solution (BSA-Cou 6 or MeB-Cou 6, $50 \mathrm{ng}$ $\mathrm{mL}^{-1}$ ), harvested, and analyzed by flow cytometry.

\section{Expression level of the TJ-associated proteins ZO-1 and occludin}

The in vitro BBB model with TEER values higher than $200 \Omega \cdot \mathrm{cm}^{2}$, was selected for western blot analysis of the $\mathrm{TJ}$-associated proteins, zonula occludens-1 (ZO-1) and occludin. BCECs were treated with BSA and MeB, $1 \mathrm{mg} \mathrm{mL}^{-1}$. After $4 \mathrm{~h}$ incubation, the cells were harvested, washed, and lysed using a lysis solution. Cell debris were removed by centrifugation at $12000 \mathrm{rpm}$ for $10 \mathrm{~min}$ at $4{ }^{\circ} \mathrm{C}$, and the supernatant analyzed by western blot analysis. 


\section{Cytotoxicity assay}

The cytotoxicity of the nanoparticles was assessed using a 3-(4,5-dimethylthiazol-2-yl)-2,5-diphenyltetrazolium bromide (MTT) assay. In brief, the cells were treated with various concentrations of nanoparticles for $48 \mathrm{~h}$, and then, cell viability was tested with an MTT kit (Sigma-Aldrich) according to the manufacturer's instructions. The cell viability was calculated as Equation (6):

$$
\text { Cell viability }(\%)=\frac{O D_{\text {experimental group }}}{O D_{\text {controlgroup }}} \times 100 \%
$$

\section{Glycolytic enzyme assay}

After incubation with the nanoparticles (Abz concentration: $2.5 \mu \mathrm{g} \mathrm{mL}^{-1}$ ) for $48 \mathrm{~h}$, the C6 cells were collected and lysed in lysis buffer $(300 \mu \mathrm{L})$. The activities of hexokinase (HK), pyruvate kinase (PK), and phosphofructokinase (PFK) were determined with hexokinase assay kit, pyruvate kinase assay kit (Nanjing Jiancheng Bioengineering Institute, Nanjing, China) and phosphofructokinase assay kit (Beijing Solarbio Science \& Technology Co., Ltd., Beijing, China), respectively. Relative enzyme activity was calculated as the percentage of the activity of the drug-treated group relative to that of the control group.

\section{Mitochondrial membrane potential analysis}

The lipophilic cation dye JC-1 was used to assess mitochondrial membrane potential (MMP, $\Delta \Psi \mathrm{m}$ ). C6 cells were treated with various nanoparticles (Abz concentration: $5 \mu \mathrm{g} \mathrm{mL}^{-1}$ ) for $48 \mathrm{~h}$. The cells were harvested and labeled with $\mathrm{JC}-1$ dye $\left(5 \mu \mathrm{g} \mathrm{mL}{ }^{-1}\right)$ at $37^{\circ} \mathrm{C}$ for $30 \mathrm{~min}$. After washing with PBS twice, the stained cells were assessed using flow cytometry. The cells treated with the nanoparticles were also tested using a phosphoenolpyruvate carboxylase (PEPC) assay kit and a citric acid assay kit (Beijing Solarbio Science \& Technology Co., Ltd.).

\section{ATP assay}

The cellular ATP concentration was measured by the UPLC method. Briefly, after treatment with various nanoparticles (Abz concentrations: $2.5 \mu \mathrm{g} \mathrm{mL}^{-1}$, SNP concentrations in different nanoparticles were kept consistent in all experiments) for $48 \mathrm{~h}$, the C6 cells were harvested, washed and lysed in $150 \mu \mathrm{L}$ lysis buffer $(500 \mu \mathrm{L}$, $1 \%$ Triton X-100, $25 \mathrm{mmol} \mathrm{L}^{-1}$ Tris, $150 \mathrm{mmol} \mathrm{L}^{-1} \mathrm{NaCl}$, $52.5 \mu \mathrm{mol} \mathrm{L}^{-1}$ EDTA). Then the buffer $(100 \mu \mathrm{L})$ was successively mixed with $\mathrm{HClO}_{4}\left(50 \mu \mathrm{L}, 0.5 \mathrm{~mol} \mathrm{~L}^{-1}\right)$, and $\mathrm{NaOH}\left(25 \mu \mathrm{L}, 1 \mathrm{~mol} \mathrm{~L}^{-1}\right)$. The mixture was centrifuged for $10 \mathrm{~min}$ at $12,000 \mathrm{rpm}$ at $4{ }^{\circ} \mathrm{C}$. The concentration of ATP in the supernatant was analyzed by UPLC with a ZORBAX SB-Aq C18 column $(5 \mu \mathrm{m}, 4.6 \times 150 \mathrm{~mm}$, Agilent Technologies, Santa Clara, CA, USA) and a mobile phase consisting of methanol and phosphate buffer $\left(0.2 \mathrm{~mol} \mathrm{~L}^{-1}, 5 \mathrm{mmol} \mathrm{L}^{-1}\right.$ TBAB, $\left.\mathrm{pH}=7.0\right)(15: 85, \mathrm{v} / \mathrm{v})$ with a flow rate of $0.5 \mathrm{~mL} \mathrm{~min}^{-1}$ at $254 \mathrm{~nm}$. All ATP concentrations were normalized to the protein contents of residual lysis buffers using the BCA protein assay kit.

\section{Cell proliferation assay}

The effect of the nanoparticles on cell proliferation was evaluated by CFDA-SE staining. The cells were labeled with CFDA-SE dye ( $5 \mu \mathrm{g} \mathrm{mL} \mathrm{m}^{-1}$ with HBSS) for $30 \mathrm{~min}$ in the dark at $37^{\circ} \mathrm{C}$. After washing with HBSS twice, the cells were exposed to the nanoparticles (Abz concentration: $0.4 \mu \mathrm{g} \mathrm{mL}^{-1}$ ) for $48 \mathrm{~h}$. Then, the cells were subjected to flow cytometry assays.

\section{Cell cycle analysis}

The C6 cells were incubated with various nanoparticles (Abz concentration: $0.4 \mu \mathrm{g} \mathrm{mL}^{-1}$ ) for $24 \mathrm{~h}$, harvested after incubation, and fixed with pre-cooled $75 \%$ ethanol at $4{ }^{\circ} \mathrm{C}$ overnight. The fixed cells were washed with PBS twice and stained with PI solution $\left(50 \mu \mathrm{gLL}^{-1} \mathrm{PI}, 0.1 \%\right.$ Triton $\mathrm{X}-100,37 \mu \mathrm{g} \mathrm{mL}^{-1}$ EDTA, and $50 \mu \mathrm{g} \mathrm{mL}^{-1}$ RNase A) for $30 \mathrm{~min}$. The samples were assessed by flow cytometry and the number of G1, S, and G2/M phase cells was determined as a percentage of the total number of cells.

\section{Apoptosis assay}

Hoechst 33342/PI double-fluorescent staining was performed to confirm apoptosis-inducing effect of the nanoparticles ${ }^{47}$. After treatment with various nanoparticles (the Abz concentration was $5 \mu \mathrm{g} \mathrm{mL}^{-1}$ ) for $48 \mathrm{~h}$, the cells were labeled with Hoechst $33342\left(5 \mu \mathrm{g} \mathrm{mL}^{-1}\right)$ and PI $\left(5 \mu \mathrm{g} \mathrm{mL}^{-1}\right)$ at $37^{\circ} \mathrm{C}$ for $30 \mathrm{~min}$ and subsequently washed with PBS three times. Apoptotic cells were detected by fluorescence microscopy. After treatment with drugs, the apoptosis of cells was assayed with flow cytometry using an Annexin V-FITC/PI double staining assay.

\section{In vivo anti-glioma effect}

To evaluate the in vivo anti-glioma activity of the nanoparticles, C6 orthotopic glioma was implanted as described in "In vivo imaging of the nanoparticles in orthotopic glioma model". Eight days after the cell injection, the mice were randomly divided into 5 groups $(n=$ 10 ) and intravenously injected with PBS, free Abz, BS$\mathrm{Abz}, \mathrm{MBS}-\mathrm{Abz}$ (Abz dose of $2.5 \mathrm{mg} \mathrm{kg}^{-1}$ ) and cisdichlorodiammine platinum (CDDP, CDDP dose of $2.5 \mathrm{mg} \mathrm{kg}^{-1}$ ) every other day.

The survival time and body weight of each group were recorded and analyzed. All animal experiments were carried out in accordance with the guidelines evaluated and approved by the ethics committee of Fudan University. When a mouse showed moribund signs including dysphagia, hemiparesis, obtundation, or weight loss of 
$>30 \%$ from the maximum weight, it was immediately sacrificed with euthanasia.

The organs (the liver, spleen, and kidneys) and glioma samples were collected from the orthotopic mouse glioma models with $10 \mathrm{~d}$ nanoparticle treatment for further in vivo energy restriction studies. In brief, $10 \%$ glioma tissue homogenates were prepared using Tissue Lyser-24 (JingXin Technology Co Ltd., Shanghai, China) with $4 \mathrm{~mm}$ ball bearings for $30 \mathrm{~s}$ at $60 \mathrm{~Hz}$. Then, the ATP level and relative activities of $\mathrm{HK}$ and PK of the samples were measured as described in the sections "ATP assay" and "Glycolytic enzyme assay". The glioma tissues were also fixed with $4 \%$ paraformaldehyde, dehydrated in 15 and $30 \%$ sucrose for $12 \mathrm{~h}$, embedded in Tissue-Tek OTC mounting medium and frozen at $-20{ }^{\circ} \mathrm{C}$, and sectioned at $20 \mu \mathrm{m}$. The slides were stained with DAPI and JC-1, and then subjected to confocal microscopy (Carl Zeiss, Oberkochen, Germany). The slides were also stained with DAPI and subjected to a deoxynucleotidyl transferasemediated dUTP nick end-labeling (TUNEL) apoptosis detection kit (FITC-labeled) and then observed under confocal microscopy. To evaluate the safety of the nanoparticles preliminarily, the slides of the organs (the liver, spleen, and kidneys) were stained with hematoxylin \& eosin for histologic examination.

\section{Results and discussion Synthesis of MeB}

The structures of the chemicals and synthetic schemes of the modified albumin are shown in Fig. S1A. First, 2iminothiolane was allowed to react with the amino residues of BSA to introduce sulfhydryl groups. Then, the thiolated BSA and para-mentha-8-thiol-3-one were crosslinked with 1,4-butanediol diglycidyl ether to form thioether bonds. The modification rate of $\mathrm{MeB}$ was $62.30 \%$. As shown in Fig. S1B, successful protein modification (lane 3, MeB) was evident from the presence of a higher-molecular-weight band and the absence of the 65 $\mathrm{kD}$ band that corresponded to unmodified BSA (lane 2). As shown in Fig. S1C, D, the retention time of MeB (11.985 min) was longer than that of BSA (7.973 min). In reverse phase HPLC, lipophilicity was related to the retention time ${ }^{48}$, with $\mathrm{MeB}$ exhibiting a higher lipophilicity than BSA due to the modification of menthol.

\section{Characterization of nanoparticles}

The preparation process of the nanoparticles is shown in Fig. S2A. The protein (BSA or MeB) was first denatured by TCEP, and then mixed with the energy inhibitors $\mathrm{Abz}$ and/or SNP to encapsulate them. The morphology, particle size, polydispersity index (PDI), and zeta potential of the nanoparticles are shown in Fig. S2B and Table S1. The TEM images (Fig. S2B) showed that BS-Abz, MBS-Abz, $\mathrm{BS}$, and MBS were nano silver spheres coated with a protein corona. The zeta potential of MBS-Abs was more negative than that of BS-Abz, which might have resulted from the reduced amino group after menthol modification. As listed in Table S1, the DL of nanoparticles with SNP (BS-Abz and MBS-Abz) was remarkably higher than that of those without SNP (B-Abz and MB-Abz). Since the surface area of nanoparticles increases correspondingly with the decrease in size, the enhanced DL of the nanoparticles with SNP was attributed to the higher specific surface area $^{49}$. As shown in Fig. S3A, the nanoparticles exhibited good stability with very minor size changes over 7 days, which indicated that the nanoparticle maintained its stability for at least 7 days. Furthermore, the relative nanoparticle size had no obvious change in 10\% FBS for $12 \mathrm{~h}$, which indicated that the nanoparticle could maintain its stability in serum (Fig. S3B).

\section{In vivo imaging in an orthotopic glioma model}

In vivo imaging analysis was used to assess the potential targeting effect of $\mathrm{MeB}$ in $\mathrm{C} 6$ glioma-bearing nude mice. As shown in Fig. 1a, the fluorescence signal was much stronger in the tumor-bearing brain of the MeB-DIR group than in the BSA-DIR group at any time postinjection, from 1 to $24 \mathrm{~h}$. Ex vivo evaluation of excised tissues (heart, liver, spleen, lung, and kidneys) showed that the nanoparticles were mainly distributed in the mononuclear phagocyte system (the liver and spleen, Fig. 1b). Ex vivo imaging (Fig. 1c) indicated an obvious glioma-bearing brain accumulation of MeB-DIR. Furthermore, the MeBDIR group displayed a significantly higher intensity than the BSA-DIR group (Fig. 1d). As in previous studies, menthone increased the $\mathrm{BBB}$ permeability of the nanoparticles, and the increased intratumoral accumulation resulted from the SPARC-albumin interaction ${ }^{44,50}$. These results suggest that nanoparticles, especially $\mathrm{MeB}$ nanoparticles, can selectively deliver drugs to the glioma bed.

\section{Nanoparticle penetration across the BBB monolayer}

The in vitro $\mathrm{BBB}$ model consisted of a monolayer of BCECs seeded on the Transwell inserts. BCECs are highly viable and can form a polarized monolayer of endothelial cells to simulate BBB in vitro ${ }^{51}$. As shown in Fig. 2a, b, free Cou 6 could not be measured in the acceptor chamber, indicating the tightness of the cell monolayer. We found that the transport efficiency of all nanoparticles increased in a time-dependent manner. The transport efficiency and the $P_{a p p}$ of MeB-Cou 6 were much higher than that of BSA-Cou 6 at all time points, implying that the penetration ability of $\mathrm{MeB}$ nanoparticles was significantly stronger than that of BSA nanoparticles due to menthol modification. As a penetration enhancer, menthol could help the drug across the physical barriers ${ }^{52}$. Such increases in the $P_{a p p}$ indicated that MeB significantly enhanced BBB penetration of the nanoparticles ${ }^{53}$. 

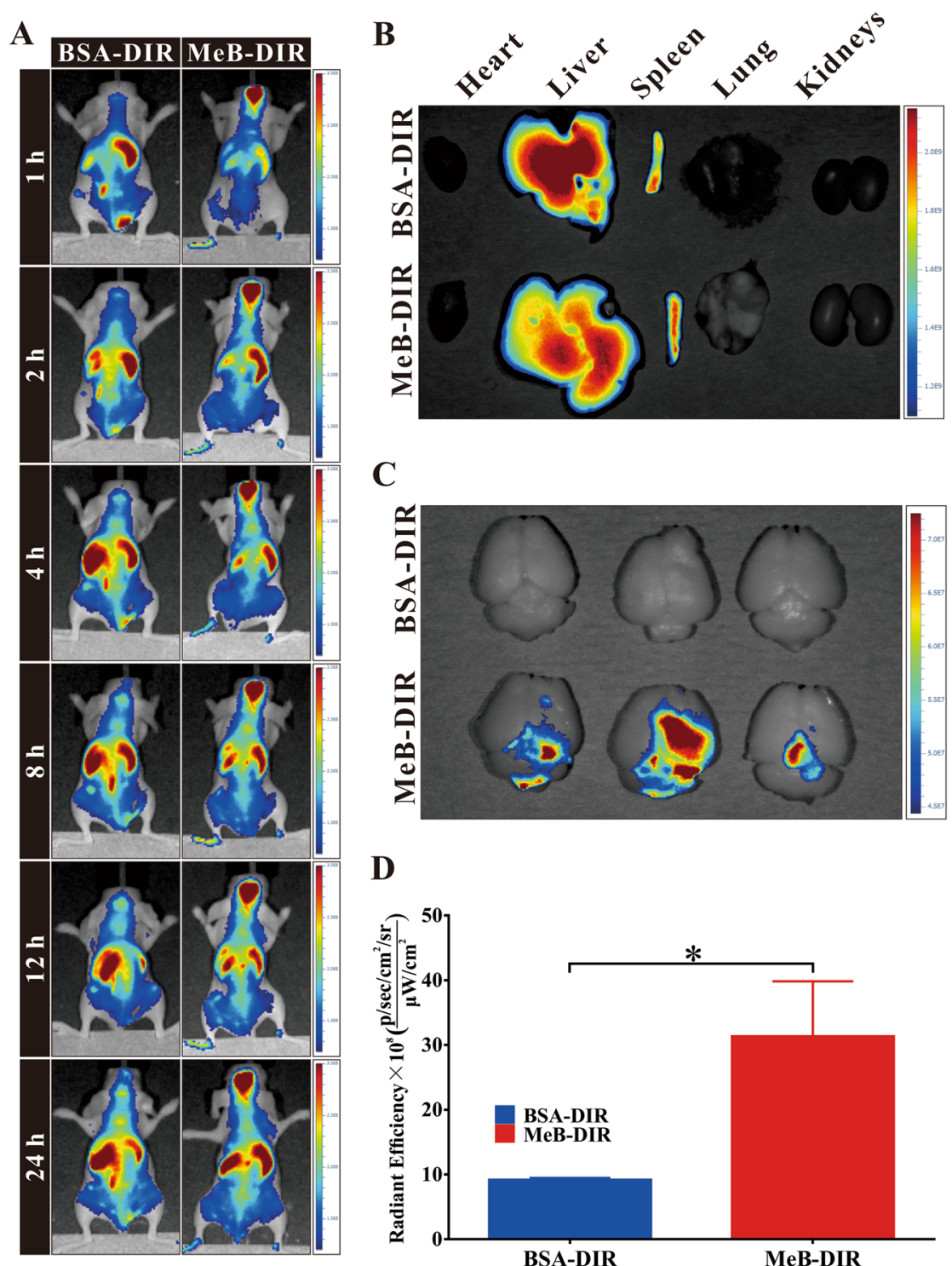

D

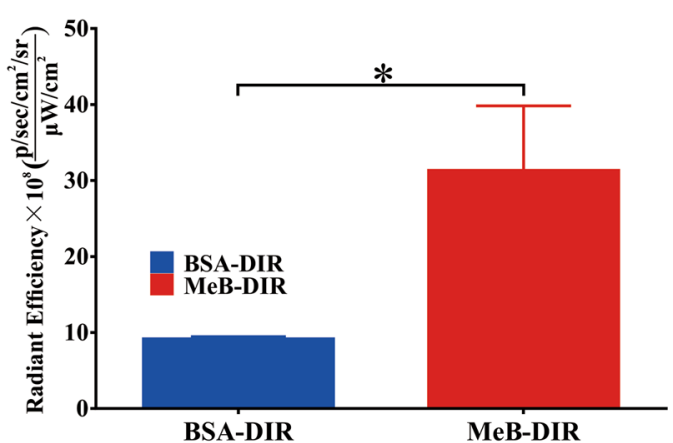

Fig. 1 a Representative in vivo real-time imaging of the orthotopic glioma model administered with different nanoparticles. $\mathbf{b}$ Ex vivo imaging of the accumulation of nanoparticles in various organs. $\mathbf{c}$ Ex vivo imaging and $\mathbf{d}$ semi-quantitative fluorescence intensity of glioma-bearing brain (data are the mean $\pm S D, n=3) . * P<0.05$ and ${ }^{* *} P<0.01$

\section{Endocytic pathway assay}

The cellular uptake of the nanoparticles was measured in BCECs and C6 glioma cells. As shown in Fig. 2e, BCECs and $\mathrm{C} 6$ cells treated with MeB-Cou 6 showed significantly higher fluorescence intensity than those treated with BSA-Cou 6. Flow cytometry showed consistent results with the qualitative analysis (Fig. 2c, d). Improved lipophilicity of carriers was reported to enhance cellular uptake $^{54,55}$ and brain penetration ${ }^{56}$, indicating these results might be due to the increased lipophilicity induced by menthol modification.

Endocytosis inhibition experiments were performed to investigate the cellular internalization mechanism for
MeB nanoparticles in BCECs and C6 cells. As shown in Fig. 2f, g, low temperature $\left(4^{\circ} \mathrm{C}\right)$ and the addition of $\mathrm{M}$ $\mathrm{CD}$ decreased the internalization of $\mathrm{MeB}$ and $\mathrm{BSA}$ nanoparticles in these cells. Most transport proteins have an optimum ability to transport at $37^{\circ} \mathrm{C}$, and low temperature hinders their activity; thus, we hypothesized that the cellular internalization of BSA and MeB nanoparticles was related to transport protein-mediated endocytosis ${ }^{57}$. In contrast to BCECs, the cellular uptake of nanoparticles in C6 cells was suppressed by pretreatment with $\mathrm{NaN}_{3}$, indicating that it was energy-dependent. The caveolae/ lipid rafts are involved in albumin internalization ${ }^{58,59}$, and cholesterol depletion by M-CD inhibits nanoparticle 


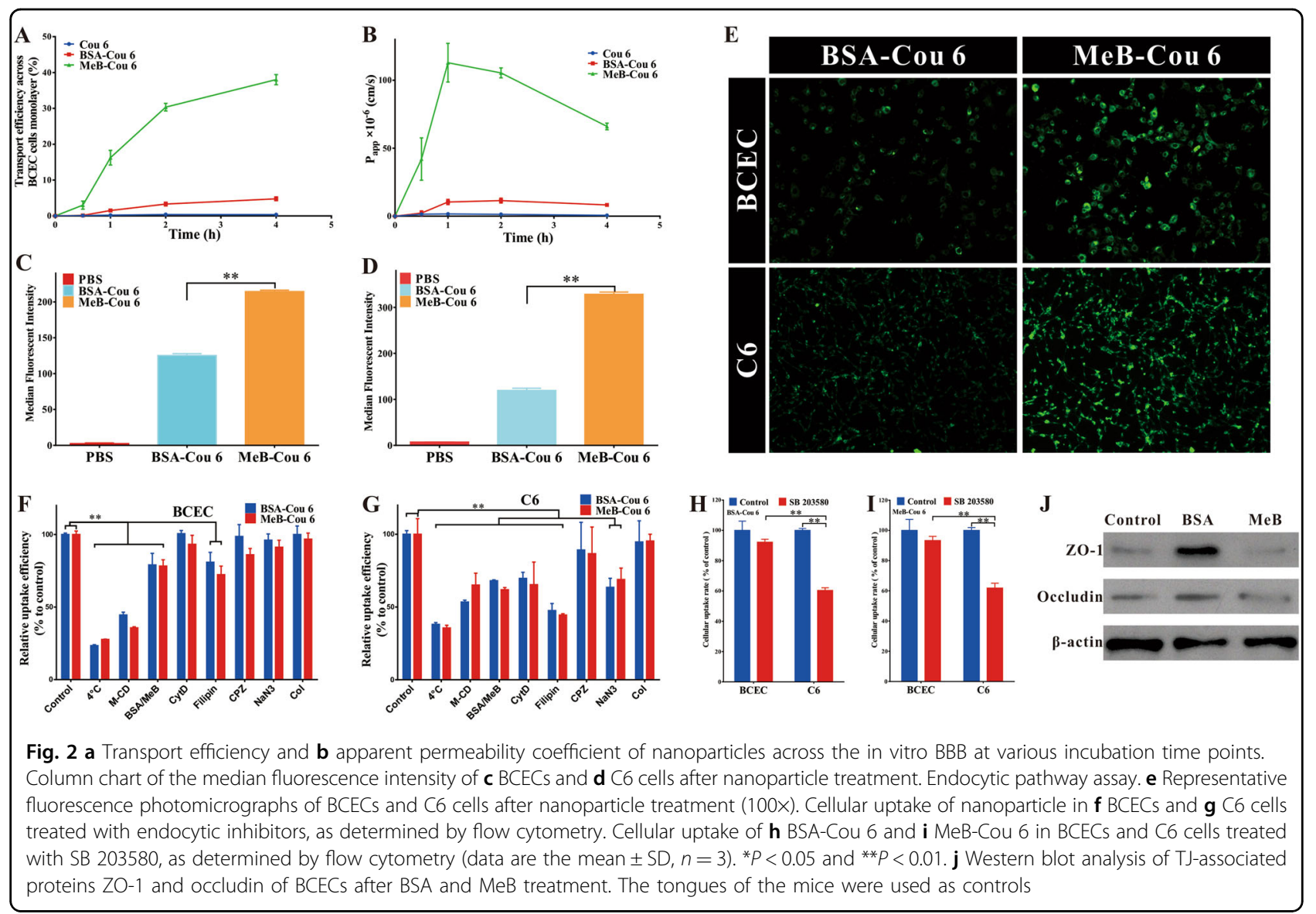

internalization. A significant decrease in cellular uptake was observed in C6 cells treated with filipin and Cyt D, indicating that the internalization of nanoparticles involved caveolae and actin-mediated endocytosis.

SPARC is an albumin-binding protein that mediates albumin internalization. C6 cells overexpressed SPARC (Fig. S4B, C) ${ }^{60,61}$. Figure $2 f$, g shows that free BSA and $\mathrm{MeB}$ could reduce cellular uptake in BCECs and C6 cells, demonstrating that the nanoparticles entered the cells through SPARC-mediated endocytosis. SB 203580 downregulates SPARC levels to inhibit SPARC-mediated internalization $^{62}$. Thus, we performed SPARC inhibition experiments to investigate the glioma targeting mechanism for MeB nanoparticles in BCECs and C6 cells. As shown in Fig. 2h, i, the internalization of the nanoparticles in C6 cells, but not BCECs, was inhibited after treatment with SB 203580. Moreover, as shown in Fig. S4, the glioma cells overexpressed SPARC, which overlapped with the distribution of the albumin nanoparticles, indicating that endocytosis of MeB nanoparticles was SPARC-dependent, and that the glioma targeting effect might be related to SPARC-mediated biomimetic transport.

\section{Expression levels of the TJ-associated proteins ZO-1 and occludin}

As shown in Fig. 2j, the BCECs in the monolayer BBB model had higher levels of ZO-1 and occludin expression compared with the normal tissue. Compared with BSA, $\mathrm{MeB}$ decreased the expression of $\mathrm{ZO}-1$ and occludin. Occludin is a major transmembrane protein localized at $\mathrm{TJs}^{63}$, while ZO-1 is a junctional adaptor protein that interacts with multiple other junctional components ${ }^{64}$. Occludin is known to associate with $\mathrm{ZO}-1^{65}$, and the down-regulation of the two proteins has been shown to increase paracellular permeability of the $\mathrm{BBB}^{65}$. As previously reported, menthol downregulated the levels of $\mathrm{TJ}$ associated proteins to induce $\mathrm{BBB}$ opening and increase $\mathrm{BBB}_{\text {penetration }}{ }^{37}$.

\section{Cellular cytotoxicity assay}

The cytotoxicity of the nanoparticles based on energy restriction was determined using the MTT assay. As shown in Fig. 3a, b, the nanoparticles (except for BS) exerted a dose-dependent growth inhibitory effect on C6 cells. The menthol modification groups (MB-Abz and MBS-Abz) and 

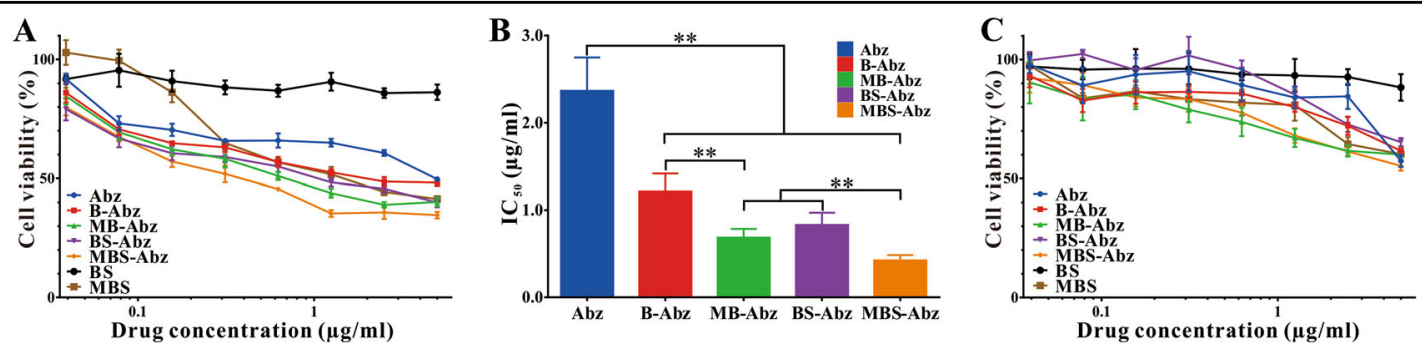

Fig. 3 MTT results after incubation with various concentrations of nanoparticles. a Cell viabilities of C6 cells in different groups. $\mathbf{b}$ The calculated IC ${ }_{50}$ values of different groups to C6 cells. c Cell viabilities of BCECs treated with different treatments $\left(n=6,{ }^{*} P<0.05\right.$ and $\left.{ }^{* *} P<0.01\right)$

co-delivery groups (BS-Abz and MBS-Abz) showed higher cytotoxicity than the unmodified (B-Abz and BS-Abz) and single drug groups (B-Abz, MB-Abz, BS and MBS) respectively, with the $\mathrm{IC}_{50}$ value of $\mathrm{MBS}-\mathrm{Abz}$ being the lowest. The cytotoxicity of the nanoparticles in BCECs (normal cells) was lower than that in C6 cells (glioma cells) (Fig. 3c). As reported previously, many tumor cells are more sensitive to ATP depletion induced by energy metabolism inhibitors than normal cells ${ }^{66}$. Thus, the selective toxicity of the nanoparticles based on energy restriction might result from the difference in energy metabolism between normal and glioma cells.

\section{Glycolytic enzyme assay}

Glioma cells tend to use glycolysis as the major pathway to generate ATP. HK, PK, and phosphofructokinase (PFK) are critical enzymes in glycolysis. HK phosphorylates glucose to glucose 6-phosphate at the initial stage of glycolysis, and PK transforms adenosine diphosphate (ADP) into ATP at the final stage ${ }^{67,68}$. Thus, glycolytic key enzymes are novel targets for glioma therapy ${ }^{69,70}$. To elucidate the ATP suppression mechanism of MBS-Abz, we investigated the effect of glycolysis in C6 cells. As shown in Fig. 4a, b, we found that the relative activities of HK and PK were significantly inhibited after treatment with the various nanoparticles, however, the nanoparticles slightly inhibited PFK activity (Fig. S5A). The menthol modification improved the inhibitory effect on HK and PK relative activities (BS-Abz vs MBS-Abz) due to its internalization-promoting ability. Moreover, both MBAbz and MBS-Abz inhibited the glycolytic pathway of energy metabolism. As the main drug in MBS-Abz, Abz inhibits the glycolytic pathway via downregulating $\mathrm{HK}$ and PK activities ${ }^{71}$.

\section{Mitochondrial membrane potential analysis}

The major function of mitochondria is ATP generation. The effect of nanoparticles on mitochondrial function was evaluated by JC-1-staining. The mitochondrial transmembrane potential (MMP, $\Delta \Psi \mathrm{m}$ ) is associated with mitochondrial function. Thus, a change in the fluorescence of JC-1 labeled cells from red (JC-1 aggregates) to green (JC-1 monomer) is an indicator of MMP dissipation $^{72}$. The flow cytometry dot plots (Fig. 4c, d) revealed a high to low MMP switch in groups treated with nanoparticles. The ratio of cells showing MMP dissipation was much higher in the case of cells treated with MeBcontaining nanoparticles (MBS-Abz/MBS) than with BSA nanoparticles (BS-Abz/BS), which might be related to the internalization-promoting effect of MeB. Meanwhile, the nanoparticles containing SNP (BS-Abz, MBS-Abz, BS, and MBS) induced more MMP dissipation than those without SNP (B-Abz and MB-Abz), but there was no obvious difference between $\mathrm{Abz}, \mathrm{B}-\mathrm{Abz}$, and MB-Abz. These results indicate that the inhibition of the mitochondrial pathway is mainly due to the dysfunction of the mitochondria targeted by SNP. In glioma cells, mitochondria still supply ATP for metabolism ${ }^{73}$. As the adjuvant drug in MBS-Abz, SNP inhibited the mitochondrial pathway via inducing mitochondrial dysfunction $^{74}$. Furthermore, Fig. S5B-C shows that the nanoparticles with the SNP could decrease the citric acid level and phosphoenolpyruvate carboxylase (PEPC) activity. In the tricarboxylic acid cycle, PEPC catalyzes the irreversible carboxylation of phosphoenolpyruvate (PEP) to form oxaloacetate, and then, acetyl-CoA combines with the oxaloacetate to form citric acid. During the course of the cycle, a decline in the amount of oxaloacetate available to combine with acetyl-CoA to synthesize citric acid could decrease the rate of ATP production by the mitochondria $^{75}$. The results indicated that the nanoparticles inhibited the PEPC activity to form oxaloacetate, and subsequently blocked citric acid and ATP generation. Therefore, the tricarboxylic acid cycle was disturbed by the SNP in the nanoparticles.

\section{ATP assay}

As ATP is the direct energy source of cells, the intracellular ATP level was determined by UPLC to evaluate the effect of nanoparticles on energy metabolism. As shown in Fig. 4e, all nanoparticles could decrease the relative ATP level when compared with PBS. The ATP inhibition of MBS-Abz was much stronger than that of BS-Abz, MB-Abz, and MBS. Since glioma cells preferred 

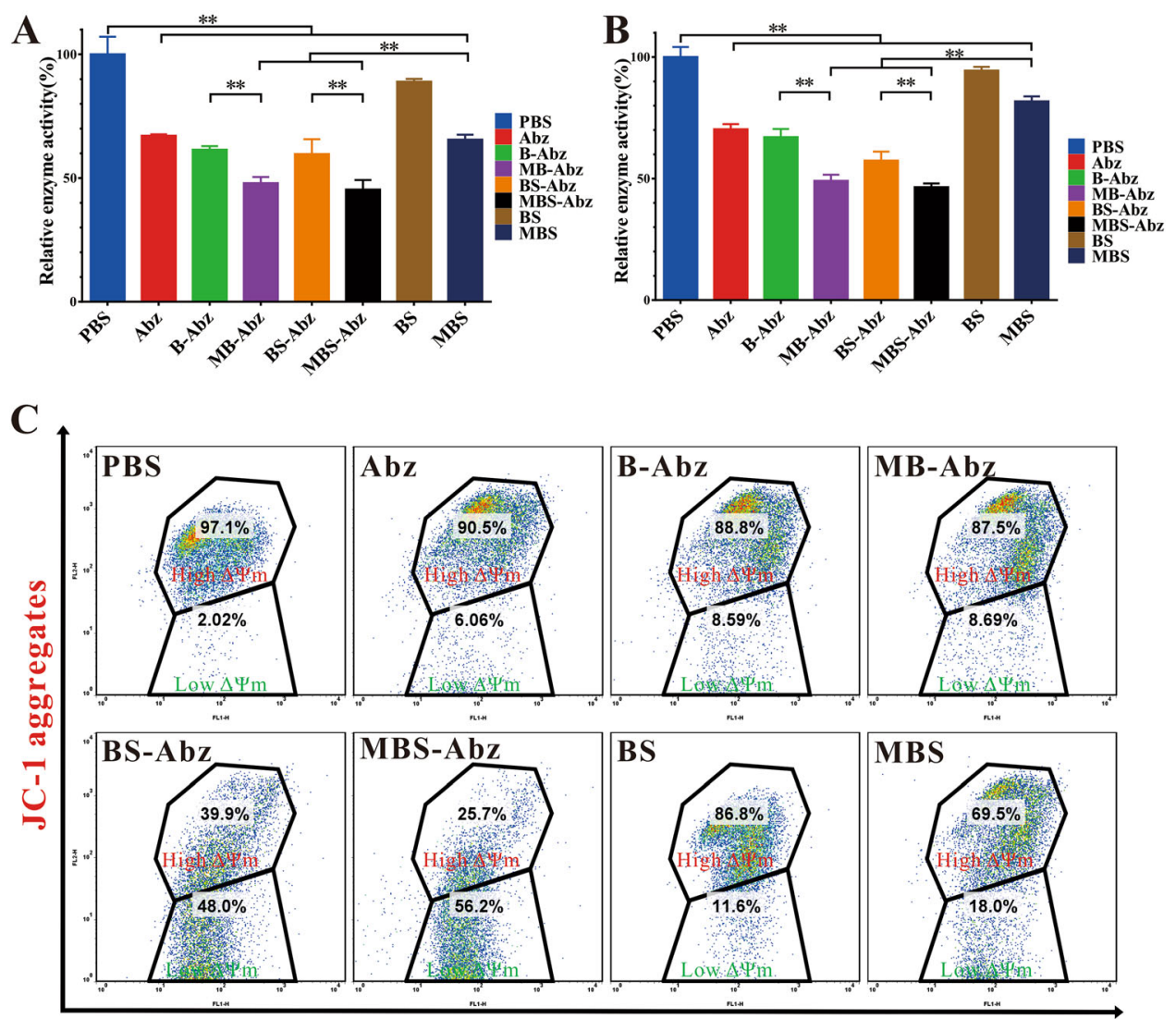

JC-1 monomers

D

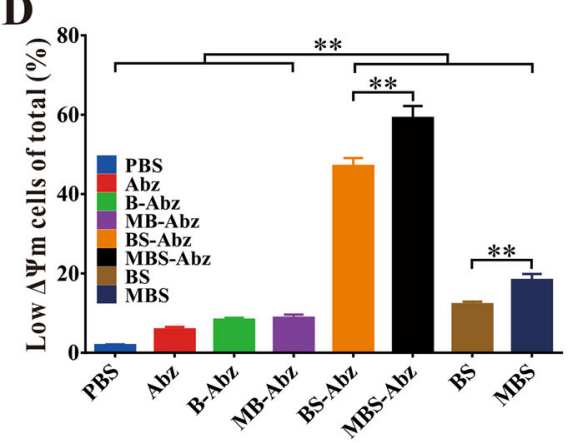

$\mathbf{E}$

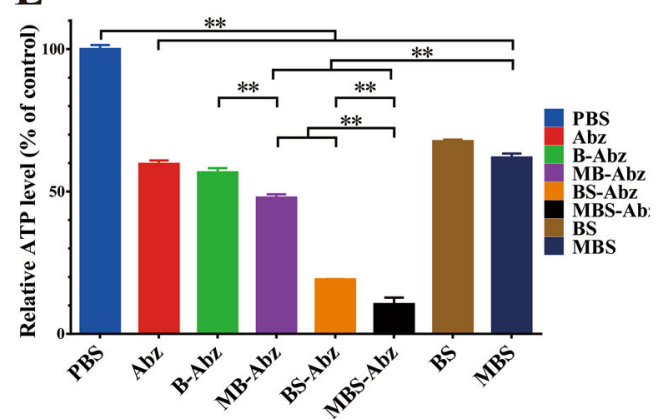

Fig. 4 The relative activity of the key enzymes $\mathbf{a}$ HK and $\mathbf{b}$ PK involved in glycolysis. Bivariate JC-1 analysis of MMP in C6 cells. $\mathbf{c}$ Column chart of low $\Delta \Psi_{\mathrm{m}}$ cell percentages. $\mathbf{d}$ Representative dot plots of the distribution of JC-1 aggregates and JC- 1 monomer. e The relative ATP level of C6 cells treated with different drugs. (data are the mean $\pm S D, n=3,{ }^{*} P<0.05$ and ${ }^{* *} P<0.01$ )

to generate ATP via the glycolytic pathway, the ATP inhibitory effect of Abz containing nanoparticles (B-Abz/ MB-Abz) was much stronger than that of SNPs (BS/MBS) (Fig. 4e). The ATP and ADP levels are shown in Fig. S5D, E. The ADP level increases with decreasing ATP levels ${ }^{76}$. The energy metabolic pathway mainly included the glycolysis pathway and the mitochondrial pathway; however, when one of the pathways was disturbed, the other pathway was stimulated to overcome the decreased formation of $\mathrm{ATP}^{15,77}$. Therefore, monotherapy could not achieve an ideal antitumor effect due to incomplete energy metabolism inhibition. As energy metabolism inhibitors, both $\mathrm{Abz}$ and nano-silver prevented the production of $\mathrm{ATP}^{78,79}$, indicating that they have a synergistic effect on the inhibition of energy metabolism. The effect was further promoted by the internalization ability of MeB, causing a strong ATP suppression, which was only approximately $10.5 \%$ of the control. 

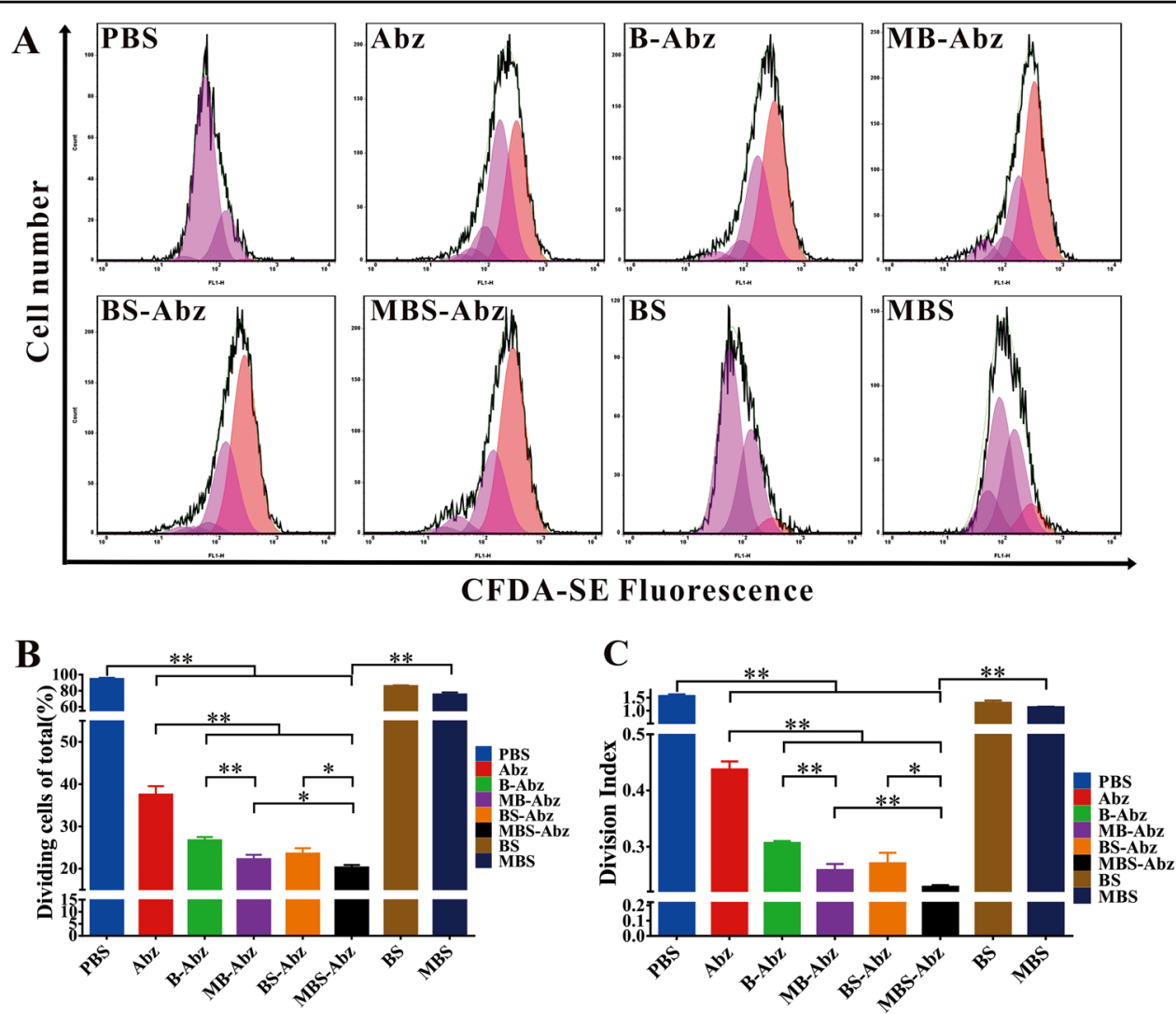

Fig. 5 Proliferation of C6 cells treated with different drugs, as measured by the CFDA-SE dye dilution method (data are the mean $\pm S D, n=3$ ). $\mathbf{a}$ Representative histograms of cell proliferation with drug stimulation. Histogram graph of $\mathbf{b}$ dividing ratio and $\mathbf{c}$ division index. ${ }^{*} P<0.05$ and ${ }^{*} P<0.01$

\section{Cell proliferation assay}

Glioma cells require abundant ATP for rapid proliferation; thus, the effect of nanoparticles on proliferation could reflect the intracellular ATP level. The proliferation of cells was quantified by monitoring CFDA-SE dilution ${ }^{80}$. As observed in Fig. 5a-c, the nanoparticles (B-Abz, MB$\mathrm{Abz}, \mathrm{BS}-\mathrm{Abz}$, and MBS-Abz) decreased the dividing ratio and division index significantly when compared with PBS. MBS-Abz showed the strongest antiproliferative effect among all other nanoparticles. These results revealed that menthol modification and the combined medication enhanced the antiproliferative effect. As glioma cells need a substantial supply of ATP for proliferation, ATP depletion could effectively stunt glioma cell proliferation $^{81}$.

\section{Cell cycle analysis}

Proliferation is associated with the cell cycle. The G1, S, and $\mathrm{G} 2 / \mathrm{M}$ phases of the cell cycle can be distinguished based on the DNA content measured by PI staining ${ }^{82}$. As shown in Fig. 6a, b, in the PBS group, most cells accumulated in the G1 phase. However, the majority of cells shifted from $G 1$ to $G 2 / M$ phase after treatment with various nanoparticles (B-Abz, MB-Abz, BS-Abz, and MBS-Abz). Moreover, menthol modification obviously enhanced G2/M phase arrest. The induction of cell cycle arrest by the nanoparticles was consistent with their antiproliferative effect. Thus, given that low ATP levels also trigger cell cycle arrest ${ }^{83}$, the altered cycle progression could have induced inhibition of glioma cell proliferation $^{84}$.

\section{Apoptosis assay}

Tumor cell apoptosis is a target for anticancer therapy. The effect of nanoparticles on cell apoptosis was estimated by Hoechst 33342/PI double staining. As shown in Fig. 7a, the nuclei of cells treated with PBS were plump and negative for PI fluorescence. After treatment with nanoparticles containing $\mathrm{Abz}$ (B-Abz, MB-Abz, BS-Abz, and MBS-Abz), the cells exhibited obvious gross nuclear abnormalities, such as multinucleation and micronuclei formation. Moreover, Fig. 7a shows that the number of 


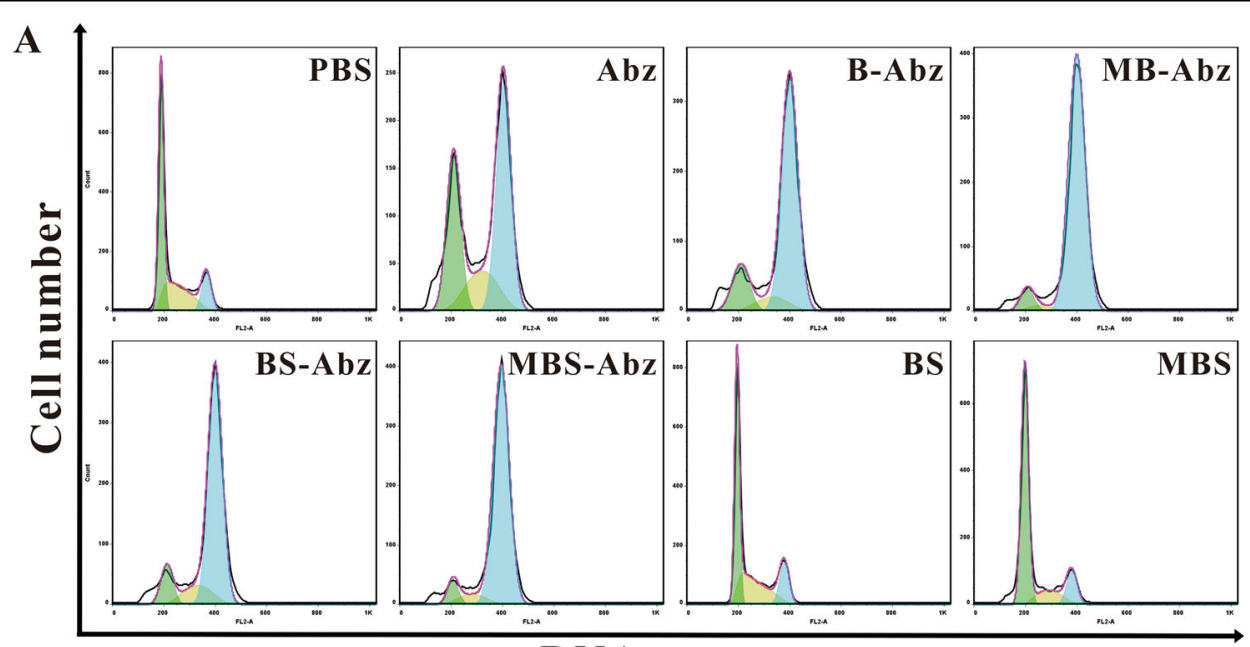

DNA content

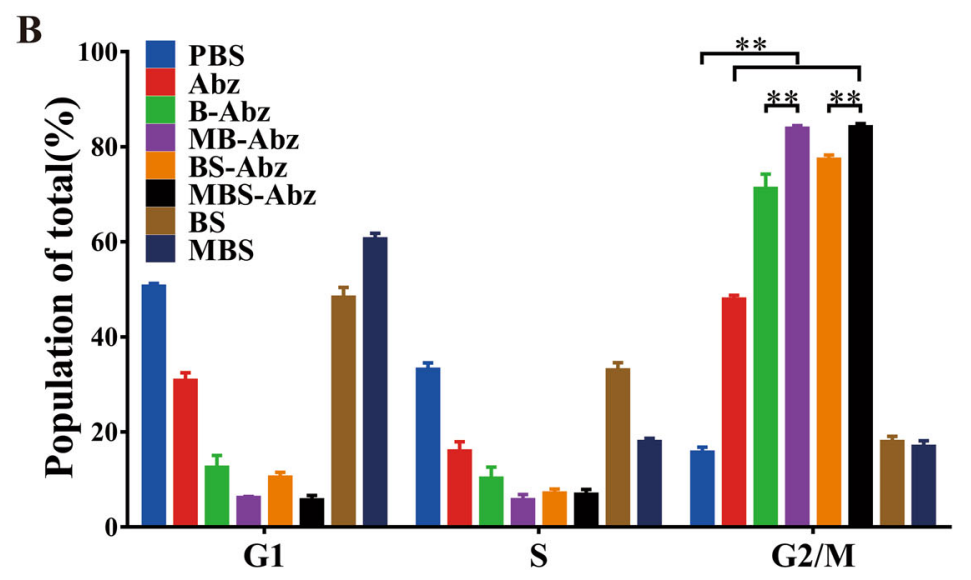

Fig. 6 Cell cycle analysis of C6 cells treated with different drugs (data are the mean $\pm S D, n=3$ ). a Representative histograms of $C 6$ cell-cycle distribution. $\mathbf{b}$ Histogram graph of the percentage of cells in G1, $S$ and G2/M phases. ${ }^{*} P<0.05$ and ${ }^{* *} P<0.01$

cells decreased sharply after nanoparticle treatment, indicating proliferation inhibition, which was consistent with Fig. 5. PI-stained nuclei, indicating the loss of membrane integrity, were observed in all groups treated with the nanoparticles. Annexin V- and PI-based apoptosis discrimination assays showed a clear induction of apoptosis in C6 cells after treatment with the nanoparticles (Fig. $7 \mathrm{~b}, \mathrm{c}$ ). Both the menthol modification and the combination of the Abz and SNP significantly increased the percentage of late apoptotic cells. Energy metabolism was a potential therapeutic target in glioma therapy, and ATP deprivation resulted in superior antiglioma efficiency though triggering apoptotic cell death ${ }^{85}$.

\section{In vivo anti-glioma effect}

The survival time of glioma-bearing mice treated with various nanoparticles was recorded to assess their therapeutic effects. As shown in Fig. 8a, the median survival time (MST) in mice treated with PBS was very short (15d), and free Abz (16 d, $P>0.05$, log-rank analysis) could not prolong it. In contrast, the MST was notably prolonged by CDDP (17 d; $P<0.05$, log-rank analysis), BSAbz (17 d; $P<0.05$, log-rank analysis), and MBS-Abz (24 d; $\mathrm{P}<0.01$, log-rank analysis) treatment, compared to PBS treatment. Among the different treatments, MBSAbz achieved the best anti-glioma effect, which was attributed to the highly efficient glioma-targeting ability of MeB.

To elucidate the mechanism of energy restriction in vivo, the effects of nanoparticles on ATP levels, and the glycolytic and mitochondrial pathways were investigated in glioma regions of the glioma-bearing brains. As shown in Fig. 8b-d, the nanoparticles decreased the intracellular ATP levels, inhibited HK and PK activities, and impeded mitochondrial function, when compared with PBS (negative control) and CDDP (positive chemotherapy 

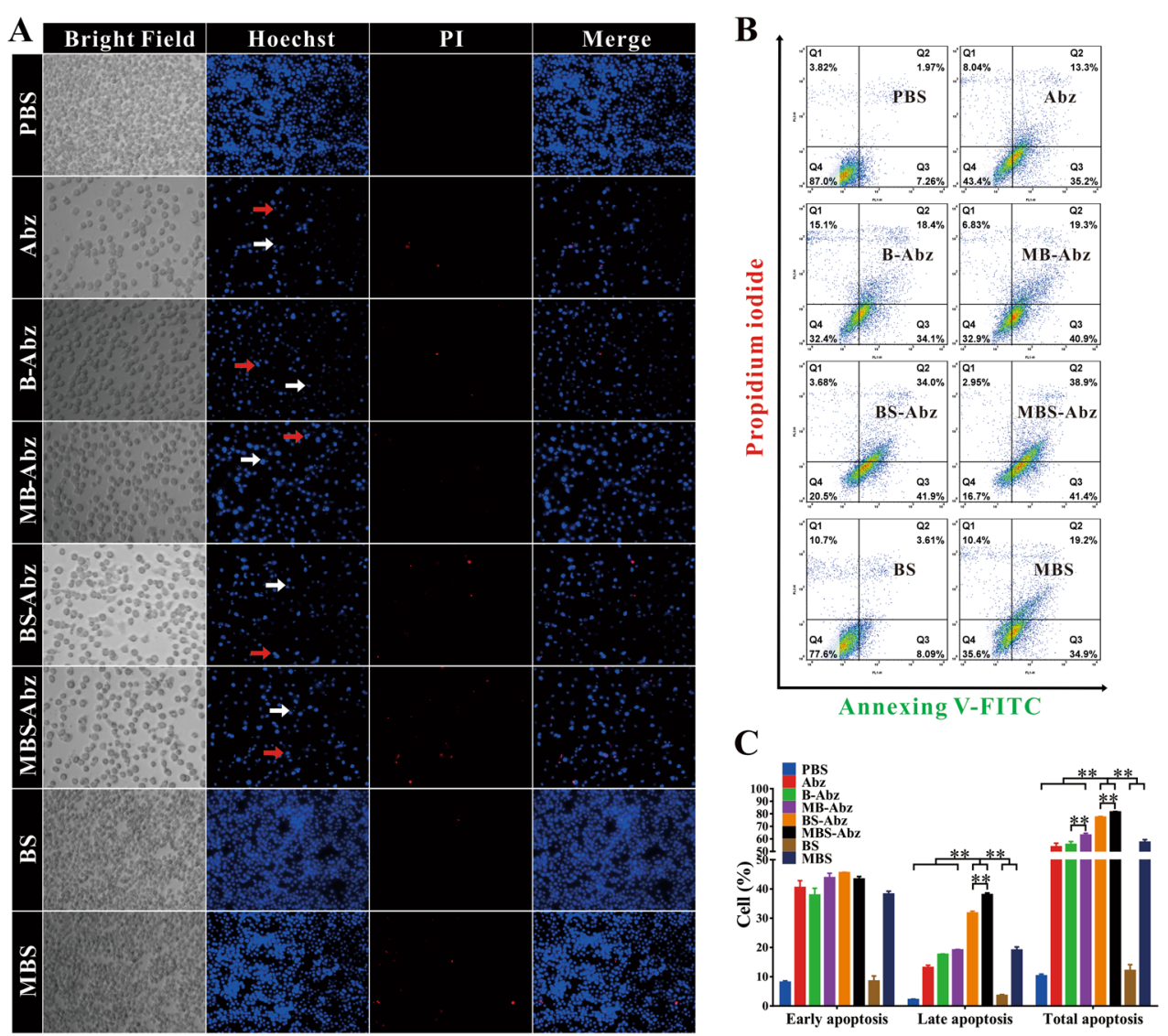

Fig. 7 a Representative fluorescence photomicrographs of morphological changes of cells detected by dual staining of Hoechst 33342/PI (100X, red arrows and white arrows indicate multinucleated cells and micronuclei, respectively). Apoptotic effects of C6 cells after drug treatment. $\mathbf{b}$ Representative scatter plots of Annexin V/PI analysis of C 6 cells after drug treatment. c Percentage of early, late and total apoptotic cells (data are the mean $\pm S D, n=3,{ }^{*} P<0.05$ and $\left.{ }^{* *} P<0.01\right)$

control). The effect of MBS-Abz was much stronger than that of BS-Abz, indicating that MBS-Abz induces ATP deprivation via glycolytic enzyme inhibition and mitochondrial dysfunction in vivo, and that the enhanced effects are attributed to the efficient and selective glioma targeting of MeB.

Next, apoptosis in glioma tissue was analyzed using.a TUNEL assay. As shown in Fig. 9, compared with the density of normal tissue, the density of glioma tissue was much higher due to the rapid proliferation of glioma cells, and clear boundaries (yellow line) were observed between the tumor and the normal tissue. Few TUNEL-positive cells were found in PBS-treated mice; however, obvious TUNELpositive cells were found to colocalize with glioma cells in drug-treated mice. The number of TUNEL-positive cells was much higher in the MBS-Abz-treated group than that in the BS-Abz-treated group. These results confirmed that efficient and selective glioma delivery of Abz and SNP by $\mathrm{MeB}$ achieves superior anti-glioma efficacy.

\section{Safety evaluation}

To assess the potential toxicity of the energy restriction strategy, we performed histopathological examinations of the main organs (liver, spleen, and kidneys) by hematoxylin and eosin (H\&E) staining. As presented in Fig. 10, the kidneys of CDDP- treated mice exhibited typical pathological changes. Partial renal tubular epithelial cells in the corticomedullary junction showed mild edema (black arrowhead) and swelling, and their cytoplasm was loose and slightly colored. The formation of tube casts was found in some renal tubules (red arrowhead in Fig. 10) and cavities of renal tubules were filled with pink proteinlike liquid. These results indicated that CDDP induced nephrotoxicity during treatment. No pathological changes were observed in mice treated with nanoparticles (BS-Abz and MBS-Abz) compared to those treated with PBS. In contrast to tumors in other organs, gliomas need safe treatments to avoid damaging brain function. We believe that the high biocompatibility of MBS-Abz is related to 

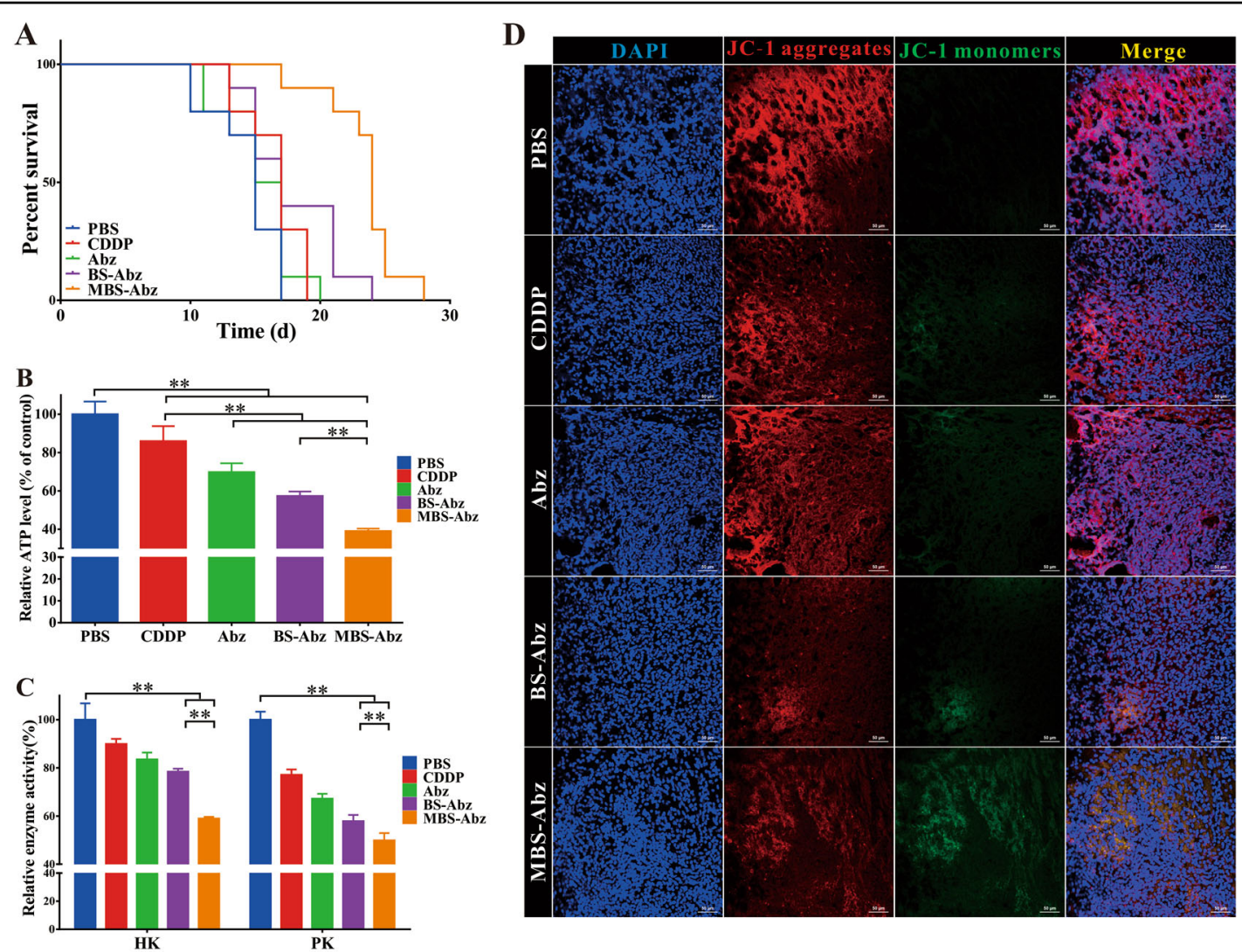

Fig. 8 a Survival curve of the brain tumor-bearing mice treated with different drugs. Data are presented as the mean $\pm S D, n=10$. $\mathbf{b}$ The relative ATP level in glioma tissues. c The relative activity of key enzymes (HK and PK) involved in glycolysis (data are the mean $\pm S D, n=3$ ). ${ }^{*} P<0.05$ and ${ }^{* *} P<$ 0.01. d Representative confocal images of JC-1-labeled mitochondria in glioma tissues

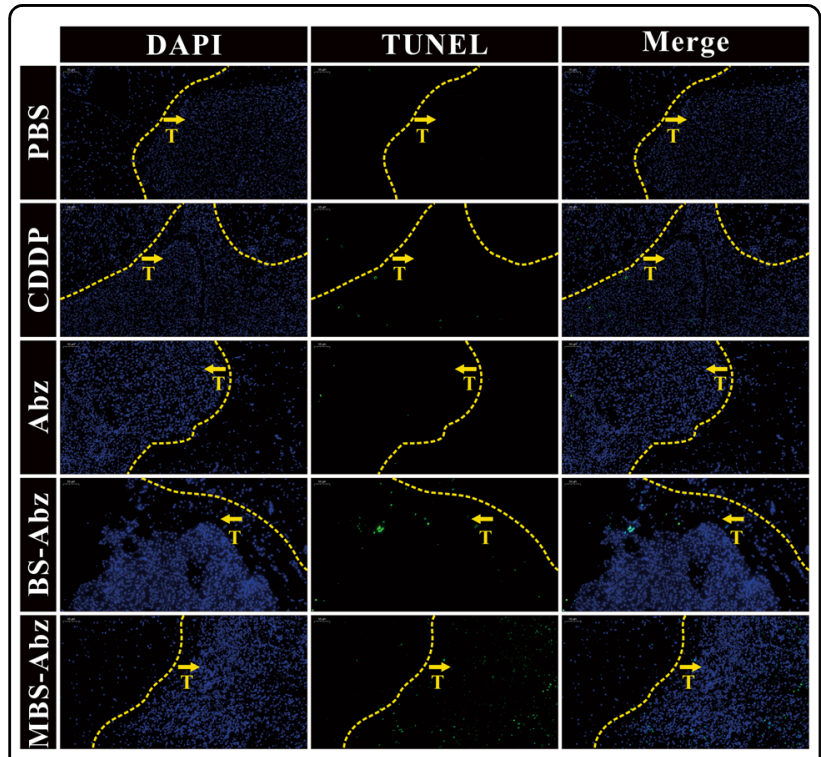

Fig. 9 TUNEL assay of glioma tissues from mice treated with different drugs the targeting effect of $\mathrm{MeB}$ and the selective inhibition of energy restriction to tumor cells.

\section{Conclusion}

In summary, in the present study, we developed a novel glioma-targeted nano-system based on BPEs and energy restriction. Based on their ability to penetrate the BBB penetration and target glioma, $\mathrm{MeB}$ nanoparticles can deliver drugs to the brain and specifically accumulate in the glioma bed. This nano-system, through the simultaneous delivery of Abz and SNP, blocked ATP synthase by inhibiting both the glycolytic and mitochondrial pathways at the same time, both in vitro and in vivo. This ATP restriction effect induced cytotoxicity, proliferation inhibition, cell cycle arrest, and apoptosis of tumor cells. The internalization-promoting effect of $\mathrm{MeB}$ could further strengthen these effects. Furthermore, MBS-Abz was most effective in inducing apoptosis in tumor cells, and significantly prolonging the MST of glioma-bearing mice. Moreover, it was tolerated by normal cells and did not cause any obvious organ toxicity in vivo. Altogether, these promising results suggest that the combination of 


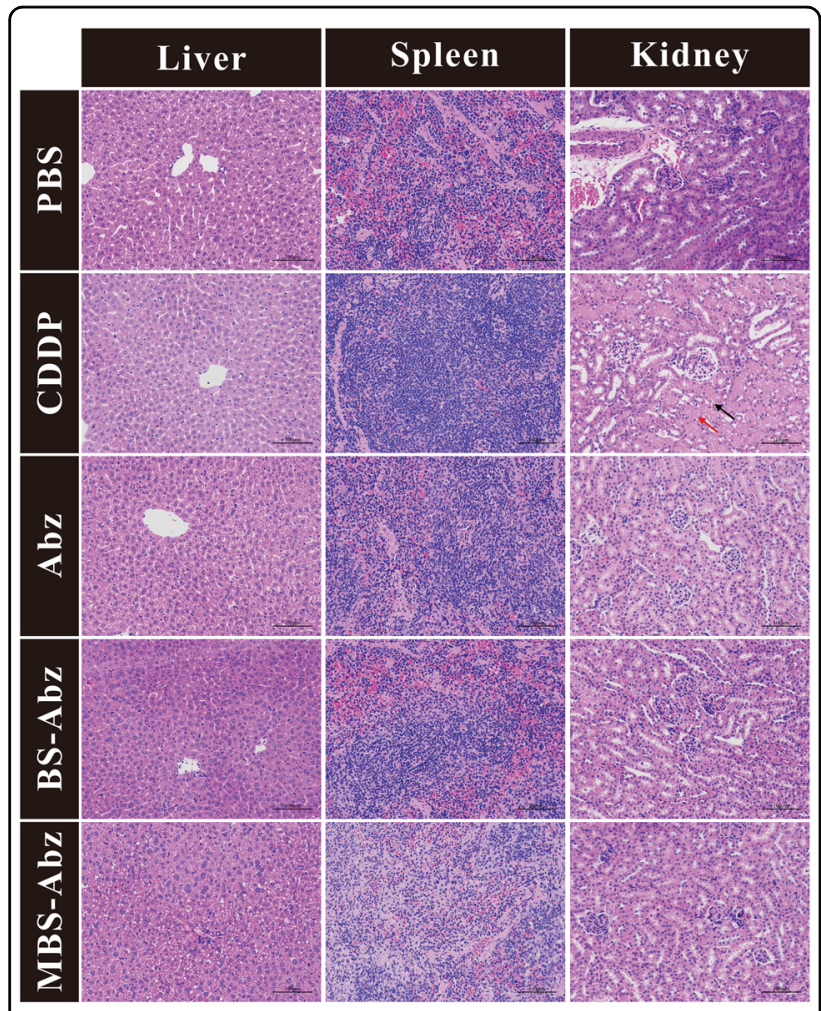

Fig. 10 Representative H\&E stained sections (200x) of the organs (the liver, spleen and kidney; black arrow: mild edema; red arrow: cast)

menthol modification of BSA and co-delivery of Abz and SNP have great potential for glioma therapy in clinical applications.

\section{Acknowledgements}

We are thankful for financial support from the National Natural Science Foundation of China (No. 81573616, 81690263 and 81773911) and the Development Project of Shanghai Peak Disciplines-Integrated Medicine (No. 20180101).

\section{Author details}

1Department of Pharmaceutics, School of Pharmacy, Fudan University \& Key Laboratory of Smart Drug Delivery, Ministry of Education, 201203 Shanghai, PR China. ${ }^{2}$ Institute of Tropical Medicine, Guangzhou University of Chinese Medicine, 510006 Guangzhou, PR China. ${ }^{3}$ Shanghai Institute of Pharmaceutical Industry, China State Institute of Pharmaceutical Industry, 285 Gebaini Rd., 201203 Shanghai, PR China. ${ }^{4}$ School of pharmacy, Chengdu University of Traditional Chinese Medicine, No1166, Liu Tai Avenue, Wenjiang District, Chengdu, PR China. ${ }^{5}$ Institute of Clinical Pharmacology, Guangzhou University of Chinese Medicine, 510006 Guangzhou, PR China. 'Shanghai Institute of Materia Medica, Chinese Academy of Sciences, 501 Haike Rd., 201203 Shanghai, PR China

\section{Conflict of interest}

The authors declare that they have no conflicts of interest.

\section{Publisher's note}

Springer Nature remains neutral with regard to jurisdictional claims in published maps and institutional affiliations.
Supplementary information is available for this paper at https://doi.org/ 10.1038/s41427-019-0138-6.

Received: 3 December 2018 Revised: 11 April 2019 Accepted: 19 April 2019 Published online: 26 July 2019

\section{References}

1. Harding, M. C. et al. Transition from cardiovascular disease to cancer as the leading cause of death in us states, 1999-2013. Circulation 133, 67 (2016).

2. Ferlay, J. et al. Cancer incidence and mortality worldwide: Sources, methods and major patterns in globocan 2012. Int. J. Cancer 136, 359-386 (2015).

3. Jr, M. M. et al. Intracarotid cisplatin chemotherapy for recurrent gliomas. J. Neurosurg. 70, 371-378 (1989).

4. Weiss, R. B., Poster, D. S. \& Penta, J. S. The nitrosoureas and pulmonary toxicity. Cancer Treat. Rev. 8, 111-125 (1981).

5. Fisher, P. G. \& Buffler, P. A. Malignant gliomas in 2005: Where to go from here? Jama 293, 615-617 (2005).

6. Milner, J. A conformation hypothesis for the suppressor and promoter functions of p53 in cell growth control and in cancer. Proc. Biol. Sci. 245, 139-145 (1991).

7. Oudard, S. et al. Mitochondria-bound hexokinase as target for therapy of malignant gliomas. Int. J. Cancer 62, 216-222 (1995).

8. Kirsch, W. M., Schulz, D., Buskirk, J. V. \& Nakane, P. Anaerobic energy metabolism in brain tumors. Prog. Exp. Tumor Res. 17, 163-191 (2015).

9. Seyfried, T. N. \& Mukherjee, P. Targeting energy metabolism in brain cancer: Review and hypothesis. Nutr. Metab. 2, 30-30 (2005).

10. Seyfried, T. N. Perspectives on brain tumor formation involving macrophages, glia, and neural stem cells. Perspect. Biol. Med. 44, 263-282 (2001).

11. Williams, Z. R., Goodman, C. B. \& Soliman, K. F. Anaerobic glycolysis protection against 1-methy-4-phenylpyridinium $(\mathrm{mpp}+)$ toxicity in $\mathrm{c} 6$ glioma cells. Neurochem. Res. 32, 1071-1080 (2007).

12. Lichtor, T. \& Dohrmann, G. J. Respiratory patterns in human brain tumors. Neurosurg 19, 896-899 (1986).

13. Kefas, B. et al. Pyruvate kinase $\mathrm{m} 2$ is a target of the tumor-suppressive microrna-326 and regulates the survival of glioma cells. Neuro-Oncol. 12, 1102-1112 (2010)

14. Hyslop, P. A. et al. Mechanisms of oxidant-mediated cell injury. The glycolytic and mitochondrial pathways of adp phosphorylation are major intracellular targets inactivated by hydrogen peroxide. J. Biol. Chem. 263, 1665-1675 (1988).

15. Gottschalk, S., Anderson, N., Hainz, C., Eckhardt, S. G. \& Serkova, N. J. Imatinib (sti571)-mediated changes in glucose metabolism in human leukemia bcr-ablpositive cells. Clin. Cancer Res. 10, 6661-6668 (2004).

16. Liang, J. et al. A novel tumor-targeting treatment strategy uses energy restriction via co-delivery of albendazole and nanosilver. Nano Res. 11, 4507-4523 (2018).

17. Pourgholami, M. H. et al. Potent inhibition of tumoral hypoxia-inducible factor 1 a by albendazole. Bmc Cancer 10, 143 (2010).

18. Pourgholami, M. H. et al. Albendazole inhibits endothelial cell migration, tube formation, vasopermeability, vegf receptor-2 expression and suppresses retinal neovascularization in rop model of angiogenesis. Biochem. Biophys. Res. Commun. 397, 729-734 (2010).

19. Noorani, L., Stenzel, M., Liang, R., Pourgholami, M. H. \& Morris, D. L. Albumin nanoparticles increase the anticancer efficacy of albendazole in ovarian cancer xenograft model. J. Nanobiotechnol. 13, 25 (2015).

20. Pourgholami, M. H. et al. Phase i clinical trial to determine maximum tolerated dose of oral albendazole in patients with advanced cancer. Cancer Chemother Pharmacol. 65, 597-605 (2010)

21. Liang, J. et al. Green synthesis of hyaluronic acid-based silver nanoparticles and their enhanced delivery to cd44+ cancer cells. RSC Adv. 5, 43733-43740 (2015).

22. Arora, S., Jain, J., Rajwade, J. M. \& Paknikar, K. M. Cellular responses induced by silver nanoparticles: In vitro studies. Toxicol. Lett. 179, 93-100 (2008).

23. Gloor, S. M. et al. Molecular and cellular permeability control at the blood-brain barrier. Brain Res. Rev. 36, 258-264 (2001).

24. Cui, Y., Xu, Q., Chow, K. H., Wang, D. \& Wang, C. H. Transferrin-conjugated magnetic silica plga nanoparticles loaded with doxorubicin and paclitaxel for brain glioma treatment. Biomaterials 34, 8511-8520 (2013). 
25. Chen, Y. C. et al. Polymersomes conjugated with des-octanoyl ghrelin for the delivery of therapeutic and imaging agents into brain tissues. Biomaterials $\mathbf{3 5}$ 2051-2065 (2014).

26. CC, S. et al. Rankings and symptom assessments of side effects from chemotherapy: Insights from experienced patients with ovarian cancer. Support. Care Cancer 13, 219-227 (2005).

27. Neuwelt, E. A. et al. Primary cns lymphoma treated with osmotic blood-brain barrier disruption: Prolonged survival and preservation of cognitive function. J. Clin. Oncol. 9, 1580-1590 (1991).

28. O'Reilly, M. A. \& Hynynen, K. Ultrasound enhanced drug delivery to the brain and central nervous system. Int. J. Hyperth. 28, 386-396 (2012).

29. Fan, C. H. et al. Folate-conjugated gene-carrying microbubbles with focused ultrasound for concurrent blood-brain barrier opening and local gene delivery. Biomaterials 106, 46-57 (2016).

30. Jiang, X. G. Brain-targeted drug delivery system. (People's Medical Publishing House, 2011).

31. Zheng, $C$. et al. Preparation and evaluation of sustained-release solid dispersions co-loading gastrodin with borneol as an oral brain-targeting enhancer. Acta Pharm. Sin. B 4, 86-93 (2014).

32. Mcginty, D., Letizia, C. S. \& Api, A. M. Fragrance material review on 3-methyl-1cyclopentadecanone. Food Cosmet. Toxicol. 49, S120-S125 (2011).

33. Thorup, I., Würtzen, G., Carstensen, J. \& Olsen, P. Short term toxicity study in rats dosed with pulegone and menthol. Toxicol. Lett. 19, 207-210 (1983).

34. Zhang, L., Han, L., Qin, J., Lu, W. \& Wang, J. The use of borneol as an enhancer for targeting aprotinin-conjugated peg-plga nanoparticles to the brain. Pharm. Res. 30, 2560-2572 (2013).

35. Gao, X. et al. Overcoming the blood-brain barrier for delivering drugs into the brain by using adenosine receptor nanoagonist. Acs Nano 8, 3678 (2014).

36. Xu, X. L. et al. A novel doxorubicin loaded folic acid conjugated pamam modified with borneol, a nature dual-functional product of reducing pamam toxicity and boosting bbb penetration. Eur. J. Pharm. Sci. 88, 178-190 (2016)

37. Zhang, L. et al. Influence of puerarin, paeoniflorin, and menthol on structure and barrier function of tight junctions in mdck and mdck-mdr1 cells. J. Tradit. Chin. Med. Sci. 2, 111-119 (2015).

38. Yang, B. et al. Influence of paeoniflorin and menthol on puerarin transport across mdck and mdck-mdr1 cells as blood-brain barrier in vitro model. J. Pharm. Pharmacol. 70, 349-360 (2017).

39. Babson, A. L. \& Winnick, T. Protein transfer in tumor-bearing rats. Cancer Res. 14, 606-611 (1954).

40. Menon, P. M., Gutierrez, J. A. \& Rempel, S. A. A study of sparc and vitronectin localization and expression in pediatric and adult gliomas: high sparc secretion correlates with decreased migration on vitronectin. Int. J. Oncol. 17 683-693 (2000).

41. Rempel, S. A. et al. Sparc: A signal of astrocytic neoplastic transformation and reactive response in human primary and xenograft gliomas. J. Neuropathol. Exp. Neurol. 57, 1112-1121 (1998).

42. Zhao, P. et al. Dual-targeting biomimetic delivery for anti-glioma activity via remodeling the tumor microenvironment and directing macrophagemediated immunotherapy. Chem. Sci. 9, 2674 (2018).

43. Lin, T. et al. Blood-brain-barrier-penetrating albumin nanoparticles for biomimetic drug delivery via albumin-binding protein pathways for antiglioma therapy. Acs Nano 10, 9999 (2016).

44. Liang, J. et al. Natural brain penetration enhancer-modified albumin nanoparticles for glioma targeting delivery. Acs Appl. Mater. Inter. 10, 30201-30213 (2018).

45. Hamidi, M. \& Zarei, N. A reversed-phase high-performance liquid chromatography method for bovine serum albumin assay in pharmaceutical dosage forms and protein/antigen delivery systems. Drug Test. Anal. 1, 214-218 (2010)

46. Potara, M., Gabudean, A. M. \& Astilean, S. Solution-phase, dual Ispr-sers plasmonic sensors of high sensitivity and stability based on chitosan-coated anisotropic silver nanoparticles. J. Mater. Chem. 21, 3625-3633 (2011).

47. Cunha, D. A. et al. Initiation and execution of lipotoxic er stress in pancreatic ß-cells. J. Cell Sci. 121, 2308-2318 (2008).

48. Decristoforo, C. \& Mather, S. J. 99m-technetium-labelled peptide-hynic conjugates: Effects of lipophilicity and stability on biodistribution. Nucl. Med. Biol. 26, 389-396 (1999).

49. Govender, T., Stolnik, S., Garnett, M. C., Illum, L. \& Davis, S. S. Plga nanoparticles prepared by nanoprecipitation: Drug loading and release studies of a water soluble drug. J. Control Release 57, 171-185 (1999).
50. Gao, C. et al. Menthol-modified casein nanoparticles loading 10hydroxycamptothecin for glioma targeting therapy. Acta Pharm. Sin. B https://doi.org/10.1016/j.apsb.2019.01.006 (2019).

51. Tsuji, A., Tamai, I., Sakata, A., Tenda, Y. \& Terasaki, T. Restricted transport of cyclosporin a across the blood-brain barrier by a multidrug transporter, $\mathrm{p}$ glycoprotein. Biochem. Pharmacol. 46, 1096-1099 (1993).

52. Wang, J. et al. Monocyclic monoterpenes as penetration enhancers of ligustrazine hydrochloride for dermal delivery. Pharm. Dev. Technol. 22, 571-577 (2017)

53. Lee, J.-A., Ha, S. K., Kim, Y.-C. \& Choi, I. Effects of friedelin on the intestinal permeability and bioavailability of apigenin. Pharmacol. Rep. 69, 1044-1048 (2017).

54. Clède, S. et al. Influence of the side-chain length on the cellular uptake and the cytotoxicity of rhenium triscarbonyl derivatives: A bimodal infrared and luminescence quantitative study. Chem 20, 8714-8722 (2014).

55. Goodchild, J. Conjugates of oligonucleotides and modified oligonucleotides: a review of their synthesis and properties. Bioconjugate Chem. 1, 165 (1990).

56. Li, J. et al. The use of myristic acid as a ligand of polyethylenimine/DNA nanoparticles for targeted gene therapy of glioblastoma. Nanotechnol 22, 435101 (2011).

57. Nedwell, D. B. Effect of low temperature on microbial growth: Lowered affinity for substrates limits growth at low temperature. Fems Microbiol. Ecol. 30, 101 (1999).

58. Wang, Z., Tiruppathi, C., Minshall, R. D. \& Malik, A. B. Size and dynamics of caveolae studied using nanoparticles in living endothelial cells. Acs Nano 3, 4110-4116 (2009).

59. Voigt, J., Christensen, J. \& Shastri, V. P. Differential uptake of nanoparticles by endothelial cells through polyelectrolytes with affinity for caveolae. Proc. Natl. Acad. Sci. USA 111, 2942 (2014).

60. Vajkoczy, P. et al. Targeting angiogenesis inhibits tumor infiltration and expression of the pro-invasive protein sparc. Int. J. Cancer 87, 261-268 (2000).

61. Schnitzer, J. E. \& Oh, P. Albondin-mediated capillary permeability to albumin Differential role of receptors in endothelial transcytosis and endocytosis of native and modified albumins. J. Biol. Chem. 269, 6072 (1994).

62. Tang, Y. et al. Codelivery of trichosanthin and albendazole by nano selfassembly for overcoming tumor multidrug resistance and metastasis. Acs Appl. Mater. Inter. 9, 26648-26664 (2017).

63. Hirase, T. et al. Occludin as a possible determinant of tight junction permeability in endothelial cells. J. Cell Sci. J. Cell Sci. 110, 1603-1613 (1997).

64. Fanning, A. S. \& Anderson, J. M. Zonula occludens-1 and-2 are cytosolic scaffolds that regulate the assembly of cellular junctions. Ann. N. Y. Acad. Sci. 1165, 113-120 (2009).

65. Furuse, $M$. et al. Direct association of occludin with zo-1 and its possible involvement in the localization of occludin at tight junctions. J. Cell Biol. 127, 1617-1626 (1994)

66. Kumagai, S., Narasaki, R. \& Hasumi, K. Glucose-dependent active atp depletion by koningic acid kills high-glycolytic cells. Biochem. Biophys. Res. Commun. $\mathbf{3 6 5}$, 362-368 (2008).

67. Macintyre, A. N. \& Rathmell, J. C. Pkm2 and the tricky balance of growth and energy in cancer. Mol. Cell 42, 713-714 (2011).

68. Marini, C. et al. Discovery of a novel glucose metabolism in cancer: the role of endoplasmic reticulum beyond glycolysis and pentose phosphate shunt. Sci. Rep. 6, 25092 (2016)

69. Floridi, A., Paggi, M. G. \& Fanciulli, M. Modulation of glycolysis in neuroe pithelial tumors. J. Neurosurg. Sci. 33, 55-64 (1989).

70. Luan, W. et al. Pkm2 promotes glucose metabolism and cell growth in gliomas through a mechanism involving a let-7a/c-myc/hnrnpa1 feedback loop. Oncotarget 6, 13006-13018 (2015).

71. Yingying, H., Nana, L., Zhibin, L. \& Shaolin, L. Effect of albendazole on glycolysis of cisplatin-resistant ovarian cancer cells. J. Third Mil. Med. Univ. 14, 1426-1429 (2012).

72. Kroemer, G. \& Reed, J. C. Mitochondrial control of cell death. Nat. Med. 6 513-519 (2000).

73. Griguer, C. E., Oliva, C. R. \& Gillespie, G. Y. Glucose metabolism heterogeneity in human and mouse malignant glioma cell lines. J. Neuro-Oncol. 74, 123-133 (2005).

74. Jeyaraj, M. et al. An investigation on the cytotoxicity and caspase-mediated apoptotic effect of biologically synthesized silver nanoparticles using podophyllum hexandrum on human cervical carcinoma cells. Colloids Surf. $B$ Biointerfaces 102, 708-717 (2013).

75. Stryer, L. Biochemistry. (W. H. Freeman and Company, 1995). 
76. Hackenbrock, C. R., Rehn, T. G., Weinbach, E. C. \& Lemasters, J. J. Oxidative phosphorylation and ultrastructural transformation in mitochondria in the intact ascites tumor cell. J. Cell Biol. 51, 123-137 (1971).

77. Oexle, H., Gnaiger, E. \& Weiss, G. Iron-dependent changes in cellular energy metabolism: influence on citric acid cycle and oxidative phosphorylation. Biochim. Biophys. Acta, Bioenerg. 1413, 99-107 (1999).

78. Lü, G. et al. Application of a cdna microarray for profiling the gene expression of echinococcus granulosus protoscoleces treated with albendazole and artemisinin. Mol. Biochem. Parasitol. 198, 59-65 (2014).

79. Lok, C.-N. et al. Proteomic analysis of the mode of antibacterial action of silver nanoparticles. J. Proteome Res. 5, 916-924 (2006).

80. Urbani, S., Caporale, R., Lombardini, L., Bosi, A. \& Saccardi, R. Use of cfda-se for evaluating the in vitro proliferation pattern of human mesenchymal stem cells. Cytotherapy 8, 243-253 (2006).
81. Akhavan, D. \& Mischel, P. S. Mtor signaling in glioblastoma: lessons learned from bench to bedside. Neuro-Oncol. 12, 882 (2010).

82. Krishan, A. Rapid flow cytofluorometric analysis of mammalian cell cycle by propidium iodide staining. J. Cell Biol. 66, 188-193 (1975),

83. Siddik, Z. H. Checkpoint controls and targets in cancer therapy. (Humana Press, 2009).

84. Su, Y. et al. Jsi-124 inhibits glioblastoma multiforme cell proliferation through $\mathrm{g}$ (2)/m cell cycle arrest and apoptosis augment. Cancer Biol. Ther. 7, 1243-1249 (2008).

85. Levesley, J., Steele, L., Taylor, C., Sinha, P. \& Lawler, S. E. Abt-263 enhances sensitivity to metformin and 2-deoxyglucose in pediatric glioma by promoting apoptotic cell death. Plos ONE 8, e64051 (2013). 